\title{
Induction of Diabetes in Aged C57B6 Mice Results in Severe Nephropathy
}

\author{
An Association with Oxidative Stress, Endoplasmic Reticulum \\ Stress, and Inflammation
}

Jin Wu, ${ }^{*}$ Ruihua Zhang, ${ }^{*}$ Massimo Torreggiani, ${ }^{*}$ Adrian Ting, ${ }^{\dagger}$ Huabao Xiong, ${ }^{\dagger}$ Gary E. Striker, ${ }^{\mp}$ Helen Vlassara, ${ }^{*}$ and Feng Zheng*

From the Division of Experimental Diabetes and Aging," the Department of Geriatrics, the Immunobiology Institute, ${ }^{\dagger}$ and the Division of Nephrology, ${ }^{\ddagger}$ the Department of Medicine, Mount Sinai School of Medicine, New York, New York

Kidney aging is a slowly progressive process that is postulated to be accelerated by intervening diseases, such as diabetes, due in part to the addition of excessive stress and inflammation from the intervening disease to the underlying aging process. This hypothesis was tested by inducing diabetes with streptozotocin in 18-month-old, aging mice. After 4 months of diabetes, these mice developed severe albuminuria, elevated creatinine levels, and renal lesions including extensive apoptotic cell death, glomerulosclerosis, afferent and efferent hyalinosis, and tubulointerstitial inflammation and fibrosis. These symptoms were associated with elevated oxidative stress. The presence of endoplasmic reticulum (ER) stress in 22-month-old diabetic kidneys resulted in up-regulation of C/EBP homologous protein (CHOP), which may play a role in increasing kidney lesions because CHOP-deficient proximal tubular cells were resistant to ER stressinduced cell death, and CHOP-deficient mice were protected from diabetic nephropathy. Moreover, CHOP-deficient mice did not develop albuminuria as they aged. Inflammation, another key component of progressive diabetic nephropathy, was prominent in 22-month-old diabetic kidneys. The expression of tumor-necrosis factor- $\alpha$ in 22-month-old diabetic kidneys may play a role in inflammation, ER stress, and apoptosis. Thus, diabetes may accelerate the underlying kidney aging process present in old mice. (Am J Pathol 2010, 176:2163-21 76; DOI: 10.2353/ajpath.2010.090386)
The prevalence of chronic and end-stage kidney disease increases with age. ${ }^{1}$ According to the Fourth US National Health and Nutrition Examination Survey (1999-2004), $23.8 \%$ of individuals older than 60 years of age and $37.8 \%$ of individuals older than 70 years of age had a moderate to severe decline in renal function ( $h$ ttp://www. cdc.gov/nchs). Reduced renal function in aging could be a significant health issue because it is a known risk factor for kidney failure and cardiovascular disease. ${ }^{2}$ The cause of declining renal function in some aging people is not clear. A process of natural biological aging may play an important role because $13 \%$ of older individuals had reduced renal function in the absence of obvious disease such as diabetes and hypertension. Excessive oxidative stress (OS) is critically involved in the overall aging process. ${ }^{3}$ There is a strong correlation between renal function and the levels of OS in aging. In addition, the levels of OS are increased in the kidneys of old animals. ${ }^{4}$ Interventions that reduce OS, ie, caloric restriction and genetic manipulations to overexpress antioxidants, prolong life span and prevent aging-related pathological changes in kidney of animals. ${ }^{5-8}$ Thus, OS may also play an essential role in kidney aging. The presence of intervening disease such as diabetes may accelerate the kidney aging process because of the addition of hyperglycemiainduced OS. Hyperglycemia stimulates mitochondrial reactive oxygen species generation and increases the formation of advanced glycation end-products (AGEs) intracellularly and extracellularly. ${ }^{9}$ Because AGEs also promote OS, a cycle of AGE formation and reactive oxygen species generation may ensue. ${ }^{10,11}$ Thus, the severity of kidney disease would be increased in aged mice

\footnotetext{
Supported by National Institutes of Health (grant 5R01-AG027628-03 to F.Z.). Accepted for publication January 11, 2010

Address reprint requests to Feng Zheng, M.D., Division of Experimental Diabetes and Aging, Department of Geriatrics, Mount Sinai School of Medicine, Box 1640, One Gustave Levy Place, New York, NY 10029. E-mail: feng.zheng@mssm.edu.
} 
rendered diabetic due partly to the superimposition of OS caused by diabetes onto the underlying aging process. We tested this hypothesis in C57B6 mice, a mouse strain that is relatively resistant to chronic kidney diseases including diabetic nephropathy at a young age but slowly develops kidney lesions with aging. ${ }^{12,13}$ We found that the induction of diabetes in perimenopausal 18-monthold C57B6 mice caused excessive OS and resulted in severe kidney lesions, with many features of diabetic nephropathy suggested by the Animal Models of Diabetic Complications Consortium. ${ }^{14}$ Because endoplasmic reticulum (ER) stress has also been shown to play an important role in aging-related diseases such as atherosclerosis and neurodegenerative diseases, ${ }^{15}$ we also examined whether ER stress was present in the aging diabetic kidney.

Inflammation is a key component of all forms of progressive chronic kidney diseases including diabetic nephropathy. ${ }^{16}$ There were severe inflammatory lesions in the aging diabetic kidney. The expression of tumor necrosis factor- $\alpha$ (TNF- $\alpha$ ) in the aging diabetic kidney may contribute to inflammation.

\section{Materials and Methods}

\section{Animals}

Four- and 17-month-old female C57B6 mice were obtained from the National Institute on Aging and were injected with streptozotocin to induce diabetes. ${ }^{12,14}$ Mice were given $50 \mu \mathrm{g} / \mathrm{g}$ streptozotocin every 3 days, for a total of five to eight injections. A total of 250 to $400 \mu \mathrm{g} / \mathrm{g}$ streptozotocin was sufficient in most mice to induce stable hyperglycemia ( $\geq 250 \mathrm{mg} / \mathrm{dl}$ ). The streptozotocin dose required to establish stable diabetes was similar between 17- and 4-month-old mice. There was less than $10 \%$ mortality in both age groups of diabetic mice with this streptozotocin protocol. Dead mice were excluded from further study. Female C57B6 mice were chosen because we have previously documented the onset and nature of their renal lesions in aging. ${ }^{13}$ They develop irregular, lengthened estrous cycles at approximately 10 to 14 months of age, and the cycles usually cease at 18 months of age. ${ }^{13}$ Mice with stable diabetes at 5 or 18 months of age were selected. Both age groups of diabetic mice were followed for 4 months without insulin treatment. Body weight and blood glucose levels were monitored weekly. Urine albumin excretion was measured biweekly using an ELISA kit (Bethyl Laboratories Inc., Houston, TX) as described previously. ${ }^{13}$ Urine creatinine levels were measured in the same samples, and the urine albumin excretion rate was expressed as the ratio of albumin to creatinine. Blood urea nitrogen levels and serum creatinine levels were examined at sacrifice. High-performance liquid chromatography was applied for determining serum creatinine levels using the method described by Yuen et al. ${ }^{17}$ In addition, to explore the role of ER stress in diabetic nephropathy, 5-month-old female C/EBP homologous protein (CHOP)-deficient mice, obtained from The Jackson Laboratory (Bar Harbor, ME) were also made diabetic by streptozotocin $(n=5)$. $\mathrm{CHOP}^{-1-}$ mice with stable diabetes were followed for 4 months.

Moreover, male $\mathrm{CHOP}^{-1-}$ mice $(n=6)$ were followed for up to 20 months of age to examine whether they developed albuminuria as seen in wild-type aging male mice $(n=10)$. The levels of urine albumin excretion were determined by enzyme-linked immunosorbent assay. Urine samples from 20-month-old $\mathrm{CHOP}^{-1-}$ and wildtype mice were also loaded onto 10\% SDS-polyacrylamide gels and separated by electrophoresis. The amount of sample loading from different mice was adjusted based on urine creatinine levels. Gels were stained with Coomassie Blue overnight, destained, and photographed.

\section{Renal Histology and Morphometry}

Mice were sacrificed 4 months after stable hyperglycemia was established. The kidneys were perfused with a saline solution, and subsequently one kidney was perfusion-fixed in situ with 4\% paraformaldehyde for histological studies. ${ }^{13}$ The tissues were embedded in glycol methacrylate or low melting paraffin and stained with periodic acid-Schiff (PAS) and Masson's trichrome. Tissues were also postfixed for 1 hour in 1.0\% osmium tetroxide, prestained in 1.25\% uranyl acetate for 1 hour, dehydrated through a series of graded alcohol solutions, and embedded in EPON epoxy resin for electron microscopy. The glomerular volume and mesangial area were determined by examining plastic-embedded sections using a digitizing tablet and video camera. ${ }^{12,13}$ The relative mesangial area was expressed as mesangial/glomerular surface area. Glomerular cell number was determined by counting the nuclear number in at least 30 glomeruli of each section. The glomerular basement membrane thickness was measured by the orthogonal intercept method on electron microscopic images. To determine the number of glomerular fenestrae, the length of fenestrated or unfenestrated glomerular capillary endothelial cytoplasm was measured. Fenestrated endothelial cell cytoplasm was generally thin, whereas the thickness of the unfenestrated endothelial cell cytoplasm was increased twice or more. ${ }^{18}$ Tubulointerstitial lesions were scored from 0 to 4 ( 0 , no changes; $1+$, changes affecting $<25 \%$ of the sample; $2+$, changes affecting 25 to $50 \%$ of the sample; $3+$, changes affecting 50 to $75 \%$ of the sample; and $4+$, changes affecting 75 to $100 \%$ of the sample) based on tubular atrophy, increase in the thickness of basement membranes and interstitial area, and clusters of inflammatory cells. ${ }^{19}$

\section{Immunohistochemistry}

Paraffin sections from nondiabetic and diabetic mice were deparaffinized before staining for apoptosis, markers for inflammation such as macrophages (F4/80, 1:100, Caltag Laboratories, Burlingame, CA) and phosphorylated nuclear factor (NF)- $\kappa \mathrm{B}$ (p65 [Ser-276], 1:25, Cell Signaling Technology, Inc., Danvers, MA), markers for 
oxidative stress, ie, nitrotyrosine (1:140, Upstate Biotechnology Inc., Billerica, MA) and malondialdehyde (MDA) (1:100, Alpha Diagnostic International Inc., San Antonio, TX), and markers for ER stress, ie, phosphorylated pancreatic ER kinase (PERK) (1:5, Santa Cruz Biotechnology, Inc., Santa Cruz, CA) and phosphorylated eukaryotic initiation factor $2 \alpha$ (elF2 $\alpha)$ (1:50, Stressgen Bioreagents Corp., Norwalk, CT).

\section{Digital Quantitation of Immunostaining}

Stained sections were examined under light microscopy (Axioskop, Carl Zeiss GmbH, Jena, Germany). The cortical area of the kidney was digitized under $\times 10$ objective low power with a Sony $3 \mathrm{CCD}$ color video camera and a meta imaging series software (Molecular Devices, Downingtown, PA). The area of positively stained tubules and glomeruli was measured and expressed as the percentage of total cortical area. The intensity of the staining was also assessed using the color differentiation program.

\section{Renal Tissue AGEs}

The amount of AGEs in kidney was determined by a competitive enzyme-linked immunosorbent assay, using monoclonal antibody reacting with $\mathrm{N}$-(carboxymethyl)lysine (4G9, Alteon, Northvale, NJ), and values were corrected to the protein concentration in the samples. $\mathrm{N}$ (Carboxymethyl)-lysine-bovine serum albumin was used as a standard for quantitation. ${ }^{6}$

\section{Oxyblot}

The oxyblot protein oxidation detection kit (Chemicon International, Temecula, CA) was used for the measurement of overall carbonyl groups introduced into the protein side chain by oxidative modification in renal tissues. 2,4-Dinitrophenylhydrazine derivatization was performed for 15 minutes following the manufacturer's instructions on $10 \mu \mathrm{g}$ of protein obtained from the kidney tissue lysate. The dinitrophenylhydrazine-derivatized protein samples were separated by $12 \%$ SDS-polyacrylamide gel electrophoresis. Proteins were transferred to polyvinylidene difluoride membranes, stained by Ponceau Red, and then probed with an anti-dinitrophenylhydrazine antibody. Blots were developed using a chemiluminescence detection system. No visible bands were seen in samples without reaction with 2,4-dinitrophenylhydrazine before Western blots (data not shown).

\section{mRNA Levels}

Total RNA was isolated from renal cortex using a PureYield RNA Midiprep kit (Promega, Madison, WI). The preparation was free of DNA contamination, and 500 ng of total RNA from each sample was reverse-transcribed as described previously. ${ }^{12,13}$ The levels of monocyte chemoattractant protein-1 (MCP-1), C-X-C motif ligand 1 (CXCL1), macrophage inflammatory protein 2 (MIP2), regulated on activa- tion, normal T cell expressed and secreted (RANTES), intracellular adhesion molecule 1 (ICAM-1), glucose regulatory protein 78 (GRP78), CHOP, and interleukin 6 (IL-6) mRNA were determined by real-time PCR. The primers used for the measurement were: MCP-1, forward 5'-AATTACCAGCAGCAAGTGTCC-3' and reverse 5'GGGTCTGCACAGATCTCCTT-3'; RANTES, forward 5'-TTCCCTGTCATCGCTTGCTCT-3' and reverse 5'-CGGATGGAGATGCCGATTTT-3'; CXCL1, forward 5'-CTTGAAGGTGTTGCCCTCAG-3' and reverse 5'-AAGGGAGCTTCAGGGTCAAG-3'; MIP2, forward 5'-TCCAGAGCTTGAGTGTGACG-3' and reverse 5'-TTCAGGGTCAAGGCAAACTT-3'; ICAM-1, forward 5'-TGCTGCAGATGCTGTGAGAGT-3' and reverse 5'-AAACCCTCGACCCATGTGATC-3'; endothelial nitric-oxide synthase (NOS), forward 5'-TACGCACCCAGAGCTTTTCT-3' and reverse 5'-CTTGGTCAACCGAACGAAGT-3'; GRP78, forward 5'-TACTCGGGGCCAAATTTGAAG-3' and reverse 5'CATGGTAGAGCGGAACAGGT-3'; and CHOP, forward 5'TATCTCATCCCCAGGAAACG-3' and reverse 5'-GGACGCAGGGTCAAGAGTAG-3'. mRNA levels were corrected by the levels of $\beta$-actin or glyceraldehyde-3-phosphate dehydrogenase (GAPDH) mRNA. The expression of TNF- $\alpha$ mRNA in kidney was determined by both real-time and regular PCR using the following primers: forward 5'GCGACGTGGAACTGGCAGAAG-3' and reverse $5^{\prime}$ GGTACAACCCATCGGCTGGCA-3'. GAPDH and $\beta$-actin mRNA levels were measured in the same sample.

\section{CHOP and ER Stress-Induced Apoptosis in Proximal Tubular Cells}

To determine whether CHOP played a role in ER stressinduced renal cell death, primary proximal tubular cells were isolated from 2-month-old $\mathrm{CHOP}^{-1-}$ and wild-type mice using a method described by Sheridan et al. ${ }^{20}$ In brief, kidneys were perfused with a phosphate buffer solution and Dynabeads M-450 $\left(5 \times 10^{5}\right.$ beads $/ \mathrm{ml}$, Invitrogen, Carlsbad, CA). Cortices were then cut into small pieces and incubated with $0.1 \%$ collagenase and 100 units $/ \mathrm{ml}$ DNase at $37^{\circ} \mathrm{C}$ for 40 minutes. After tissues were pressed through a 100- $\mu \mathrm{m}$ cell strainer (BD Biosciences, Bedford, MA) with a syringe plunger, glomeruli were removed by a magnetic concentrator. The remaining tissues were collected with a 40- $\mu \mathrm{m}$ cell strainer, washed, and cultured with medium containing Dulbecco's modified Eagle's medium/F12 (1:1), $5 \mu \mathrm{g} / \mathrm{ml}$ transferrin, 5 $\mu \mathrm{g} / \mathrm{ml}$ insulin, $50 \mathrm{nmol} / \mathrm{L}$ hydrocortisone, $5 \%$ fetal bovine serum (FBS), and 100 units $/ \mathrm{ml}$ each of penicillin and streptomycin. Cells isolated by this method were predominantly of proximal tubular origin ( $>90 \%$ ) and were characterized by their cobblestone appearance and by positive staining for aquaporin-1 and megalin (Santa Cruz Biotechnology, Inc.). Cells $\left(1 \times 10^{4} /\right.$ well in a 24-well plate) from $\mathrm{CHOP}^{-1-}$ and wild-type mice were exposed to 0.6 to $1.2 \mu \mathrm{g} / \mathrm{ml}$ of tunicamycin. Twenty-four hours later, cells were gently washed and stained with trypan blue, and the number of live cells from each well was counted. 
Table 1. General Characteristics of Diabetic Mice

\begin{tabular}{lccccc}
\hline & \multicolumn{2}{c}{ Young mice $(9$ months $)$} & & \multicolumn{2}{c}{ Old mice $(22$ months $)$} \\
\cline { 2 - 3 } Measurements & Control $(n=6)$ & Diabetic $(n=7)$ & & Control $(n=10)$ & Diabetic $(n=11)$ \\
\hline Body weight $(\mathrm{g})$ & $23.4 \pm 2.8$ & $21.4 \pm 3.2$ & & $25.7 \pm 1.4$ & $24.4 \pm 0.5$ \\
Heart weight $(\mathrm{mg})$ & $116 \pm 11$ & $121 \pm 12$ & & $167 \pm 19$ & $169 \pm 23$ \\
Kidney weight $(\mathrm{mg})$ & $197 \pm 16$ & $194 \pm 22$ & & $218 \pm 11$ & $225 \pm 19$ \\
Glucose $(\mathrm{mg} / \mathrm{dL})$ & $124 \pm 28$ & $397 \pm 42$ & & $106 \pm 34$ & $301 \pm 36$ \\
Blood urea nitrogen $(\mathrm{mg} / \mathrm{dL})$ & $19.1 \pm 4.5$ & $20.6 \pm 7.3$ & & $15.8 \pm 2.5$ & $24.5 \pm 8.9$ \\
Serum creatinine $(\mathrm{mg} / \mathrm{dL})$ & $0.119 \pm 0.01$ & $0.121 \pm 0.04$ & & $0.109 \pm 0.03$ & $0.138 \pm 0.02^{*}$ \\
\hline
\end{tabular}

${ }^{*} P<0.05$ versus old mice control.

\section{TNF- $\alpha$-Induced Expression of Proinflammatory Genes, ER Stress, and Apoptosis in Proximal Tubular Cells}

A proximal tubular cell line obtained from mice transgenic for Simian virus 40 T antigen was grown in Dulbecco's modified Eagle's medium containing 10\% FBS. ${ }^{21}$ For the measurement of TNF- $\alpha$-stimulated gene expression, $1 \times$ $10^{5}$ proximal tubular cells were transferred to each well of a six-well plate. After the cells were placed in $0.1 \%$ FBS medium for 24 hours, $10 \mathrm{ng} / \mathrm{ml}$ of TNF- $\alpha$ was added to test wells. Total RNA was isolated from all wells 4 hours later. MCP-1, RANTES, CXCL1, MIP-2, ICAM-1, and inducible NOS mRNA levels were determined by real-time PCR as described above and corrected by $\beta$-actin mRNA levels. TNF- $\alpha$-stimulated MCP-1 and RANTES production and release into the medium were measured in TNF- $\alpha$ (10 $\mathrm{ng} / \mathrm{ml}$ )-treated and control cells at 24 hours. The amount of MCP-1 or RANTES in the medium was measured by ELISA (Invitrogen).

To determine whether TNF- $\alpha$ induced ER stress in proximal tubular cells, $1 \times 10^{6}$ cells were transferred to $4-\mathrm{cm}^{2}$ Petri dishes. After medium was switched from $10 \%$ to $0.1 \%$ FBS, some dishes were treated with TNF- $\alpha$ (25 $\mathrm{ng} / \mathrm{ml}$ ). Total RNA and protein were collected from cells at 4, 12, and 24 hours. GRP78 mRNA levels were determined by real-time PCR. CHOP and phosphorylated and total elF2 $\alpha$ protein levels were measured by Western blots using the antibodies shown above.

The effect of TNF- $\alpha$ on apoptotic cell death was determined by adding increasing concentrations of TNF- $\alpha$ ( 5 to $25 \mathrm{ng} / \mathrm{ml}$ ) to cultured proximal tubular cells under normal serum conditions (10\% FBS). Here $2 \times 10^{5}$ proximal tubular cells were transferred to each well of a sixwell plate, and some cells were treated with TNF- $\alpha$. Cells in both supernatants and attachment were collected 24 hours later and stained for annexin $V$. The number of annexin V-positive cells in the total cell population was counted by flow cytometry. Negative controls included cells stained without the first or the second antibody or without antibody. DNA and protein were also collected from cells in the media and from the plate for assessing DNA laddering and for blotting to determine whether caspase 3 was activated (1:1000, Cell Signaling Technology, Inc.).

\section{TNF- $\alpha$-Induced Increase in Albumin Permeability in Podocytes}

Podocytes $\left(1 \times 10^{5}\right)$ were seeded onto collagen-coated transwell filters $(0.4 \mu \mathrm{mol} / \mathrm{L}$ pore size, Corning Inc., Corning, NY) placed in the top chamber of each well of a 24-well plate. After cells reached confluence, some wells of cells were treated with TNF- $\alpha(20 \mathrm{ng} / \mathrm{ml})$ in $2 \%$ FBS medium for 8 hours. Then the medium from both the top and bottom chambers was completely removed, cells were washed twice with PBS, and the top chamber was refilled with $0.2 \mathrm{ml}$ of $2 \% \mathrm{FBS}$ medium supplemented with $0.5 \mathrm{mg} / \mathrm{ml}$ fluorescein isothiocyanate (FITC)-labeled bovine serum albumin (BSA) (Sigma-Aldrich, St. Louis, MI), whereas the bottom chamber was refilled with $0.6 \mathrm{ml}$ of $2 \%$ FBS medium supplemented with $0.5 \mathrm{mg} / \mathrm{ml}$ unlabeled BSA. At different time points, $100-\mu$ l aliquots were collected from the bottom chamber, and fluorescence was measured by a fluorescence spectrophotometer $(485 \mathrm{~nm}$ excitation and $535 \mathrm{~nm}$ emission). The concentration of FITC-BSA passing through the monolayer was determined by reference to a set of standard dilutions of FITC-BSA. The value of albumin flux through the untreated monolayer was arbitrarily defined as $100 \%$.

\section{Statistical Analysis}

Values are expressed as means \pm SD. Analysis of variance or a two-tailed unpaired $t$-test was used to evaluate the differences between the means. Significance was defined as $P<0.05$.

\section{Results}

\section{General}

Body weight was slightly decreased in both 9- and 22month-old diabetic mice (Table 1). There was a significant increase in the heart weight/body weight ratio in 22-month-old nondiabetic mice compared with that in 9-month-old nondiabetic mice (Table 1). The presence of hyperglycemia for 4 months increased the heart weight/ body weight ratio in both 22- and 9-month-old diabetic mice. There were no differences in the kidney weight/ body weight ratio between diabetic and nondiabetic mice. The serum creatinine levels in 22-month-old dia- 
A

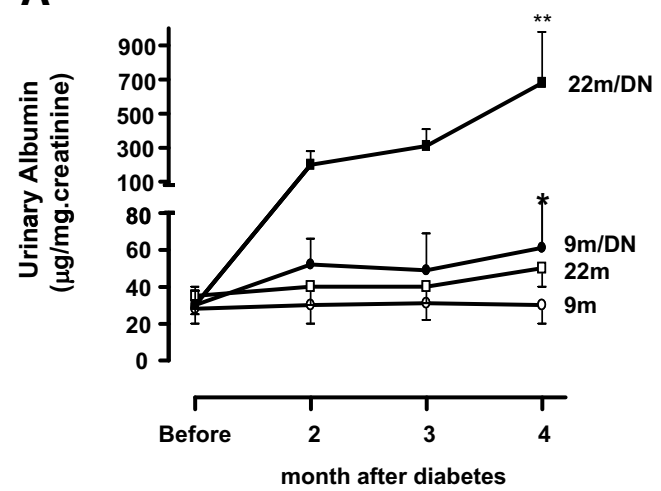

B

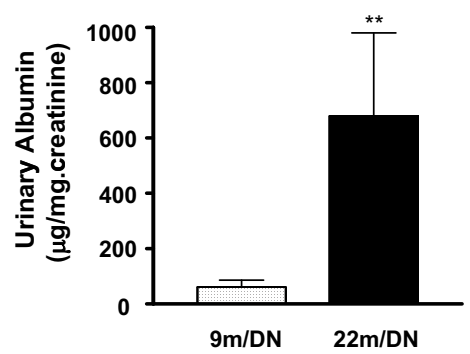

Figure 1. Progressive increase in urine albumin excretion in 22-month-old diabetic mice. A: 22 month-old $(22 \mathrm{~m})$ C57B6 female mice did not have obvious albuminuria. Urinary albumin was slightly but significantly elevated in 9-month-old diabetic mice $(9 \mathrm{~m} / \mathrm{DN}) ; 22$-month-old diabetic mice developed severe and progressive albuminuria $(22 \mathrm{~m} / \mathrm{DN}) .{ }^{*} P<0.05$ versus 9 -monthold nondiabetic mice $(9 \mathrm{~m})$; **ak $P<0.01$ versus $9 \mathrm{~m} /$ DN. B: The levels of albuminuria in 22-month-old mice after 4 months of hyperglycemia were 11 -fold higher than those in 9-month-old mice after 4 months of hyperglycemia. betic mice were significantly higher than those in agematched nondiabetic mice. The blood urea nitrogen levels were increased in 4 of 11 22-month-old diabetic mice (>35 mg/dl) but were normal in 22-month-old nondiabetic and in 9-month-old diabetic mice.

\section{Albuminuria}

As reported previously, young C57B6 mice were relatively resistant to diabetic nephropathy. ${ }^{12,22}$ There was a mild increase in urine albumin excretion in 9-month-old diabetic mice (albumin/creatinine ratio: diabetic $61 \pm 25$ $\mu \mathrm{g} / \mathrm{mg}$ creatinine versus nondiabetic $30 \pm 10 \mu \mathrm{g} / \mathrm{mg}$ creatinine, $P<0.05$ ) (Figure 1A). On the other hand, 22-month-old diabetic mice developed progressively severe albuminuria. After 2 months of diabetes the albumin/ creatinine ratio was already higher in 20-month-old diabetic mice than in either 22-month-old nondiabetic or 9-month-old diabetic mice, and it continued to increase after 4 months of diabetes, reaching levels that were 11-fold higher than in 9-month-old diabetic mice (Figure 1B).

\section{Renal Histology}

Compared with 9-month-old normal mice (Figure 2A), 9-month-old diabetic mice exhibited diffuse, mild glomerular lesions, characterized by glomerular hypertrophy and a small increase in the mesangial areas (Figure 2B). There were no tubulointerstitial or vascular lesions in 9-month-old diabetic mice. As reported previously, 22month-old nondiabetic mice had prominent glomerular hypertrophy, a slight increase in the mesangial areas, and a largely normal tubulointerstitium (Figure 2C). ${ }^{13}$ In contrast, 22-month-old diabetic mice developed severe glomerular, tubulointerstitial, and vascular lesions (Figure 2, D-F). There was also an increase in overall glomerular cell number $(49.5 \pm 4.9$ nuclei/glomerulus versus $43.7 \pm$ 8.5 nuclei/glomerulus in 22-month-old control, $P<0.05$ ). The mesangium was diffusely and markedly enlarged (Figure 2, D-F). The basement membranes of Bowman's capsules were markedly thickened and duplicated and obsolescent glomeruli were more frequently encountered than in age-matched 22-month-old nondiabetic mice. There was a decrease in the size of most glomerular vascular spaces, although dilated loops were occasion- ally encountered. The walls of afferent and efferent glomerular arterioles were noticeably thickened by a prominent increase in homogeneous PAS-positive materials, ie, hyalinosis (Figure 2E, arrows). The walls of small arterioles had a significantly increased width due to fibrosis and/or an increased cell number, including foam cells (Figure 2D, arrow). Morphometric analysis revealed that
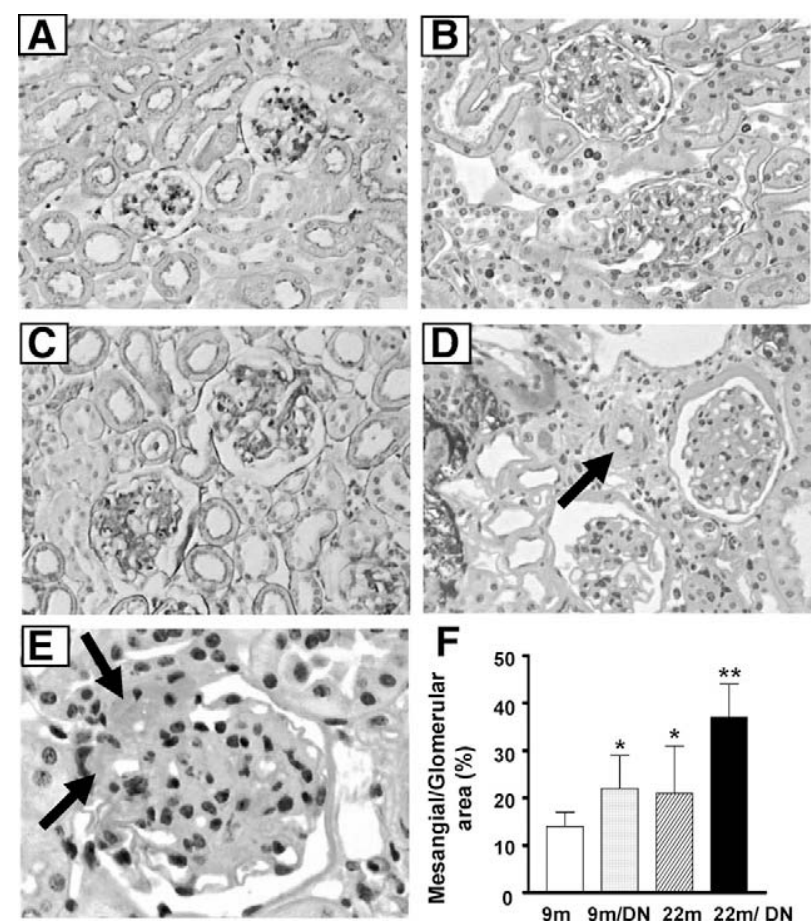

Figure 2. Severe nephropathy in 22-month-old diabetic mice. A: 9-monthold mice: normal glomeruli and tubulointerstitium (PAS; original magnification, $\times 200$ ). B: 9-month-old diabetic mice: increased glomerular size and mesangial areas (PAS; original magnification, $\times 200$ ). C: 22 -month-old mice increased glomerular size (PAS; original magnification, $\times 200$ ). D: 22-monthold diabetic mice: enlarged glomeruli with significant expansion of mesangial areas are seen (PAS; original magnification, $\times 200$ ). Bowman's capsule and tubular basement membranes are thickened. The width of arteriolar walls is increased (arrow). There are tubular atrophy and widened interstitial spaces. E: 22-month-old diabetic mice: the walls of afferent (upper arrow) and efferent (lower arrow) arterioles are thickened and filled with homogeneous PAS-positive materials. There is a prominent expansion of mesangial area (PAS; original magnification, $\times 400)$. F: The mesangial area, expressed as a percentage of total glomerular area, was increased in the kidneys of both 22-month-old control mice and 9-month-old diabetic mice, but it was more prominent in the kidneys of 22-month-old diabetic mice. ${ }^{*} P<0.05$ versus $9 \mathrm{~m}$. ${ }^{* * *} P<0.01$ versus $9 \mathrm{~m} / \mathrm{DN}$ or $22 \mathrm{~m}$. 

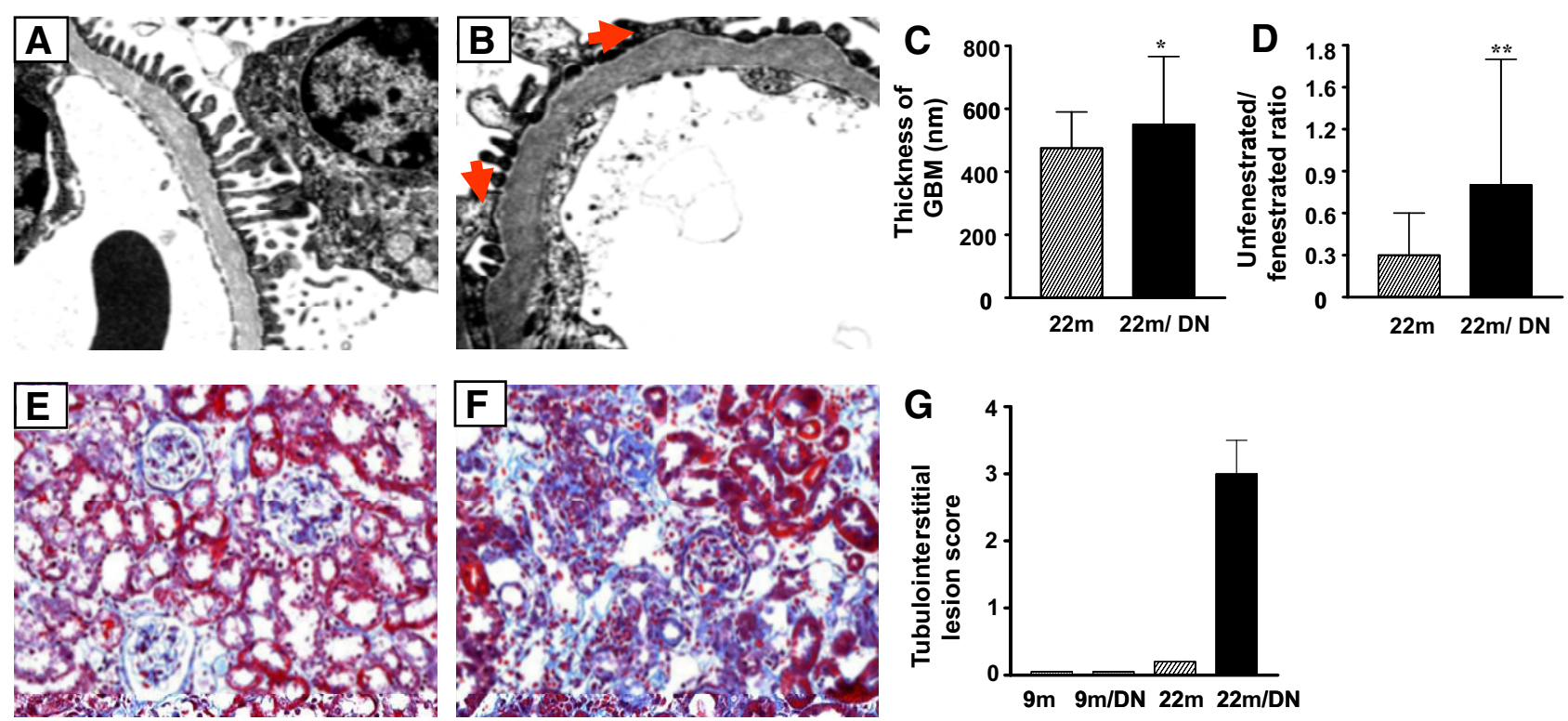

Figure 3. Changes in glomerular basement membrane and fenestration and tubulointerstitium in 22-month-old diabetic mice. A: Glomerular basement membrane is uniform and the podocyte foot processes are relatively normal in 22-month-old mice (electron micrograph; original magnification, $\times 5000$ ). B: The basement membrane is irregularly thickened, and there is fusion of foot processes in 22-month-old diabetic mice (arrows, electron micrograph; original magnification, $\times 5000)$. C: Quantitative analysis showed that the glomerular basement membrane (GBM) thickness was significantly increased in 22 -month-old diabetic mice. ${ }^{*} P<0.05$ versus $22 \mathrm{~m}$. D: Quantitative analysis showed that glomerular fenestration was reduced in 22-month-old diabetic mice. Data are expressed as the ratio of unfenestrated to fenestrated glomerular endothelia. ${ }^{* * *} P<0.01$ versus $22 \mathrm{~m}$. E: Representative Masson's trichrome stain of kidneys from 22 -month-old nondiabetic mice. Whereas blue staining (matrix) is increased in glomeruli, the tubulointerstitium is relatively normal (original magnification, 200 $\times$ ). F: Representative Masson's trichrome stain of kidney from 22-month-old diabetic mice. Severe tubulointerstitial lesions characterized by tubular atrophy, interstitial fibrosis, and extensive inflammatory cell infiltration are present. G: Semiquantitative measurement of tubulointerstitial lesions. Tubulointerstitial changes were not present in the kidneys of 9-month-old nondiabetic $(9 \mathrm{~m})$ and 9-month-old diabetic $(9 \mathrm{~m} / \mathrm{DN})$. Tubulointerstitial lesions were mild in 22 -month-old nondiabetic mice but were severe in the kidneys of 22 -month-old diabetic mice $(22 \mathrm{~m} / \mathrm{DN})$. The average score of tubulointerstitial lesions in 22 -month-old diabetic mice was $3+$.

the glomerular volume was increased in 9-month-old diabetic mice and was further increased in 22-month-old nondiabetic and 22-month-old diabetic mice. There was no difference in glomerular volume between 22-monthold diabetic mice $\left(3.8 \pm 0.7 \times 10^{5} \mu \mathrm{m}^{3}\right)$ and 22-monthold control mice $\left(3.3 \pm 0.7 \times 10^{5} \mu \mathrm{m}^{3}\right)$. However, the mesangial area was significantly enlarged (Figure $2 \mathrm{~F}$ ), and glomerular basement membranes appeared thickened in 22-month-old diabetic mice (Figure 2, D and E).

Examination of electron micrographs revealed that the thickness of glomerular basement membranes was generally, but irregularly, increased in 22-month-old mice and further increased in 22-month-old diabetic mice (Figure $3, A-C)$. Fusion of podocyte foot processes was seen in some peripheral loops of 22-month-old diabetic mice (Figure 3B, arrows). The number of fenestrae in glomerular capillary endothelial cells was significant decreased in 22-month-old diabetic mice (Figure 3, B and D). Tubular atrophy and loss of tubular structures were prominent changes, in association with expansion of the interstitial space due to loss of tubules, fibrosis, and an extensive, diffuse infiltration of inflammatory cells (Figure 3, E-G).

\section{Apoptosis}

To further characterize the lesions and explore the underlying mechanism(s) of increased cellular injury in 22month-old diabetic mice, the number of apoptotic cells was determined by terminal deoxynucleotidyl transferase dUTP nick-end labeling staining. There was a prominent increase in the number of apoptotic cells in 22-month-old diabetic kidneys (Figure 4, A and B). Dead cells were mostly located in tubules and the interstitium. In contrast, terminal deoxynucleotidyl transferase dUTP nick-end labeling-positive cells were rarely found in 9-month-old nondiabetic kidneys and were only occasionally seen in 9-month-old diabetic kidneys. There were few apoptotic cells in 22-month-old nondiabetic kidneys (Figure 4B).

\section{Oxidative Stress}

Because oxidative stress is closely associated with aging and is an important cause of apoptotic cell death, we examined the levels of oxidative stress in 22-month-old diabetic kidneys. Kidney AGE levels were elevated in
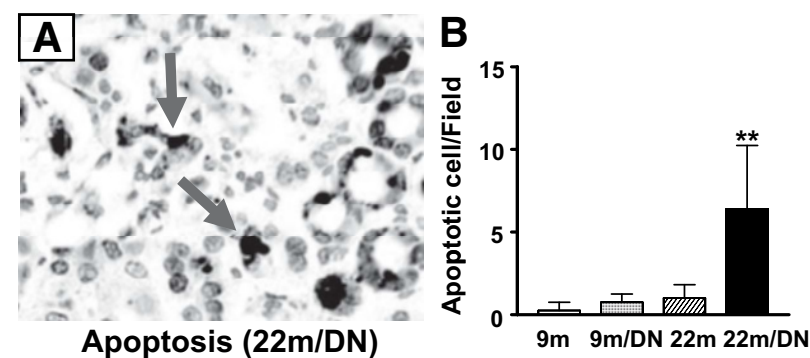

Figure 4. Apoptosis in the kidneys of 22-month-old diabetic mice. A: Immunostaining for apoptotic cells in the kidneys of 22-month-old diabetic mice (original magnification, $\times 400$ ). Cells with positive nuclear staining are marked by arrows. B: Apoptotic cells were rarely seen in the kidneys of 9-month-old nondiabetic mice $(9 \mathrm{~m})$ and were occasionally seen in the kidneys of 9 -month-old diabetic $(9 \mathrm{~m} / \mathrm{DN})$ and 22 -month-old nondiabetic mice $(22 \mathrm{~m})$. There was a sixfold increase in the number of apoptotic cells in the kidneys of 22 -month-old diabetic mice ( $22 \mathrm{~m} / \mathrm{DN})$. ${ }^{* * *} P<0.01$ versus $22 \mathrm{~m}$. 

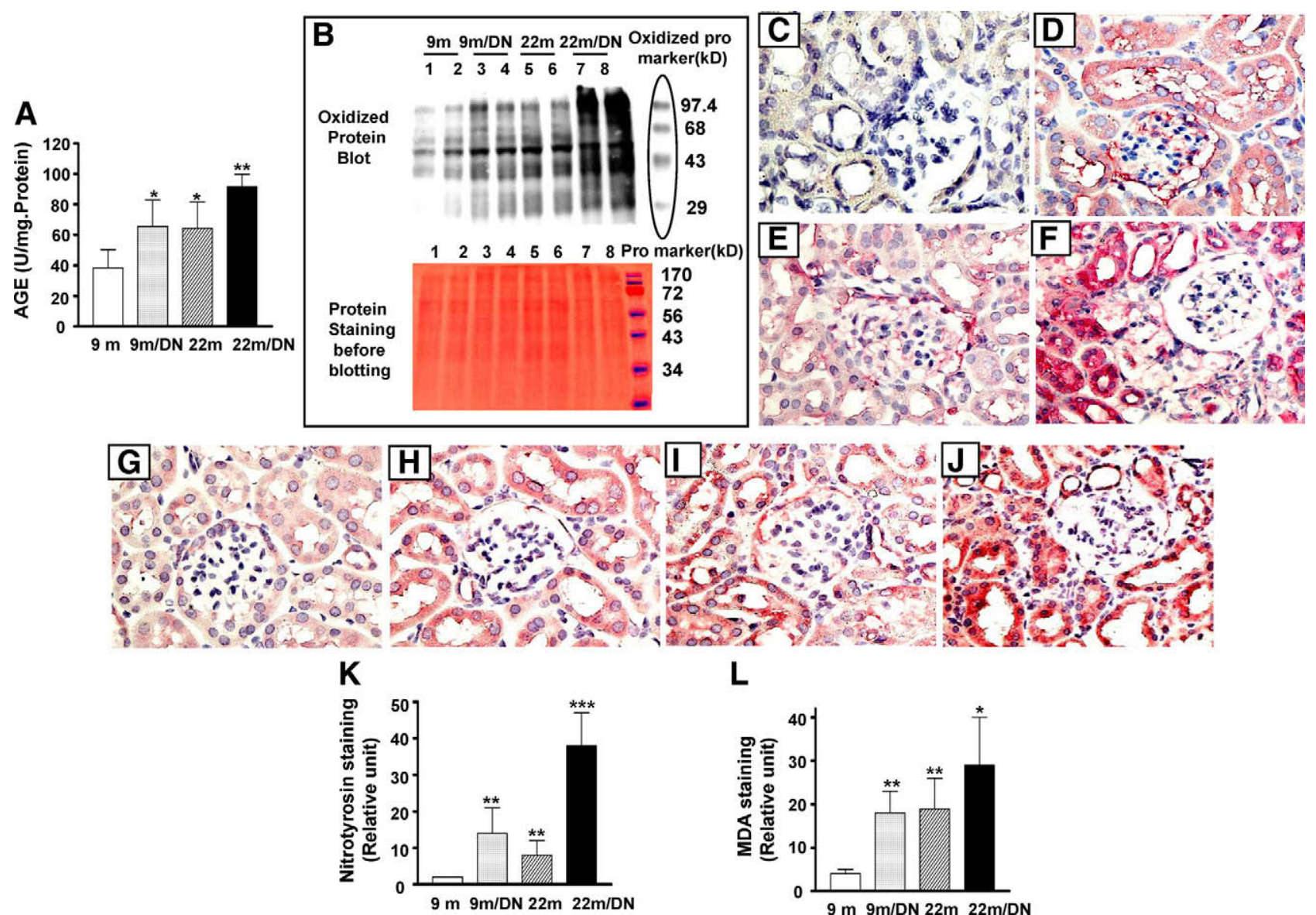

L

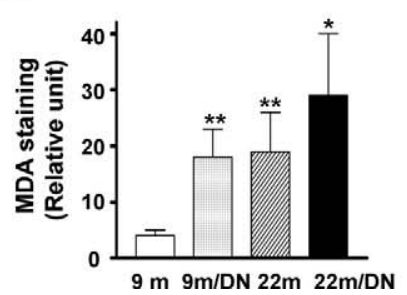

Figure 5. Oxidative stress in the kidneys of 22-month-old diabetic mice. A: The kidney AGE content was measured by competitive enzyme-linked immunosorbent assay and expressed as a ratio relative to protein concentrations (mg). AGE accumulation was evident in 9-month-old diabetic mice ( $9 \mathrm{~m} / \mathrm{DN})$ and in 22 -month-old nondiabetic mice $(22 \mathrm{~m})$ and was further increased in kidneys of 22 -month-old diabetic mice $(22 \mathrm{~m} / \mathrm{DN})$. ${ }^{*} P<0.01$ versus 9 -month-old mice $(9 \mathrm{~m})$; ${ }_{* *}^{*} P<0.05$ versus $9 \mathrm{~m} / \mathrm{DN}$ or $22 \mathrm{~m}$. B: The levels of protein oxidation in the kidneys of 9-month-old (9m), 9-month-old diabetic (9m/DN), 22-month-old (22m), and 22 -month-old diabetic mice $(22 \mathrm{~m} / \mathrm{DN})$ were determined by Western blot using a specific anti-oxidized protein antibody. Representative gels of two animals from each group show that, although the bands of oxidized protein are visible in samples of the kidneys from 9-month-old mice (upper gel, $9 \mathrm{~m}$, lanes $\mathbf{1}$ and 2), stronger bands with a similar pattern of proteins are seen in kidney samples from 9-month-old diabetic mice (upper gel, $9 \mathrm{~m} / \mathrm{DN}$, lanes $\mathbf{3}$ and $\mathbf{4})$ and 22 -month-old mice (upper gel, 22m, lanes 5 and 6). Protein oxidation is markedly increased in kidneys from 22 -month-old diabetic mice (upper gel, $22 \mathrm{~m} / \mathrm{DN}$, lanes 7 and $\mathbf{8}$ ). Known oxidized proteins of different molecular weights are used as markers of protein size and as a positive control for Western blots. The lower panel shows the same gel stained with Ponceau red before Western blotting with the antioxidized protein antibody: $10 \mu \mathrm{g}$ of kidney protein from 9-month-old (lanes 1 and 2), 9-month-old diabetic (lanes 3 and 4), 22-month-old (lanes 5 and 6), and 22-month-old diabetic (lanes 7 and 8) mice was loaded on a SDS-polyacrylamide gel. Note that the regular protein markers shown on the lower gel are not detected by the antioxidized protein antibody and therefore cannot be seen in upper gel. C-F:. Immunostaining for nitrotyrosine of kidneys from 9-month-old (C) (original magnification, $\times 400$ ), 9-month-old diabetic (D) (original magnification, $\times 400$ ), 22-month-old (E) (original magnification, $\times 400$ ), and 22-month-old diabetic (F) (original magnification, $\times 400)$ mice. The staining is nearly absent in 9-month-old nondiabetic kidney (C) and is clearly visible in glomeruli and tubules of 9-month-old diabetic kidneys (D). The 22-month-old diabetic kidney exhibits the strongest nitrotyrosine staining (F). MDA immunostaining in kidneys from 9-month-old (G) (original magnification, $\times 400$ ), 9-month-old diabetic (H) (original magnification, $\times 400$ ), 22-month-old (I) (original magnification, $\times 400$ ), and 22-month-old diabetic (J) (original magnification, $\times 400)$ mice. The staining is more intense in 9-month-old diabetic and 22-month-old nondiabetic (H and $\mathbf{I})$ and further increased in 22 -month-old diabetic kidneys (J). The intensity of immunostaining was measured by morphometry software and defined by an arbitrary unit. Both nitrotyrosine (K) and MDA (L) staining were quantitatively increased in 9-month-old diabetic and 22-month-old nondiabetic kidneys compared with 9-month-old nondiabetic kidneys. The staining was further increased in 22 -month-old diabetic kidneys. ${ }^{* * *} P<0.01$ versus 9 -month-old nondiabetic $(9 \mathrm{~m})$; ${ }^{*} P<0.05$, **** $P<0.01$ versus 22 -month-old nondiabetic $(22 \mathrm{~m})$.

9-month-old diabetic and 22-month-old nondiabetic mice compared with 9-month-old nondiabetic mice. Although the levels of kidney AGEs were comparable between 9-monthold diabetic and 22-month-old nondiabetic mice (Figure $5 A$ ), the levels of AGEs in kidneys of 22-month-old diabetic mice were higher than those in either 9-month-old diabetic or 22-month-old nondiabetic mice (Figure 5A).

The amount of oxidized proteins in kidney was increased in the kidneys of 9-month-old diabetic (Figure 5B, lanes 3 and 4) and 22-month-old nondiabetic mice (Figure 5B, lanes 5 and 6) compared with that in 9-monthold nondiabetic mice (Figure 5B, lanes 1 and 2). The increase was comparable between kidneys of 22-month- old nondiabetic mice and 9-month-old diabetic mice. The amount of oxidized proteins was greatest in kidneys of 22-month-old diabetic mice (Figure 5B, lanes 7 and 8).

Protein nitration, as demonstrated by staining tissue with an anti-nitrotyrosine antibody, was increased in the kidneys of 9-month-old diabetic and 22-month-old nondiabetic mice but was barely visible in the kidneys of 9-month-old nondiabetic mice (Figure 5, C-E). A more prominent increase in the intensity of nitrotyrosine staining was found in 22-month-old diabetic kidneys, particularly in the cytoplasm of tubular cells (Figure 5F). The cause of increased nitrotyrosine is not clear. The levels of renal endothelial NOS mRNA were comparable between 
A
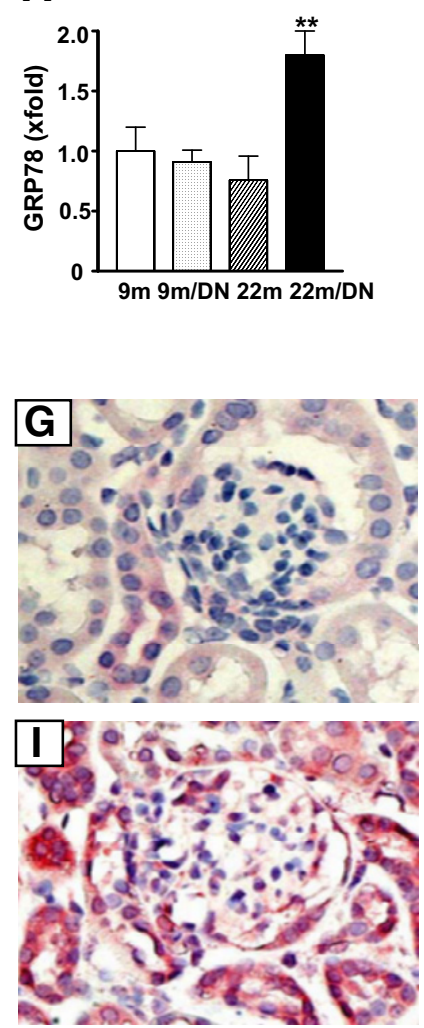

B
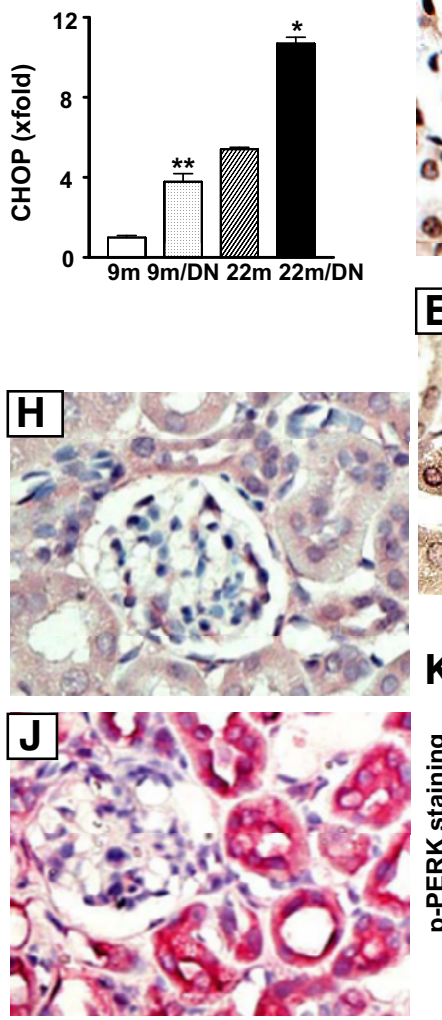
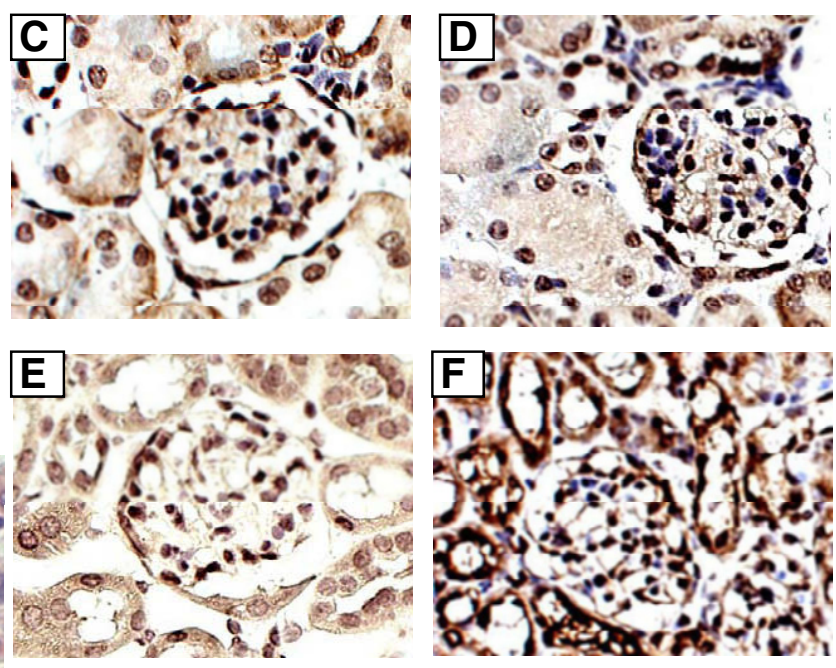

$\mathbf{L}$

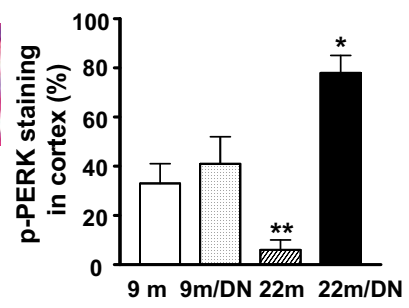

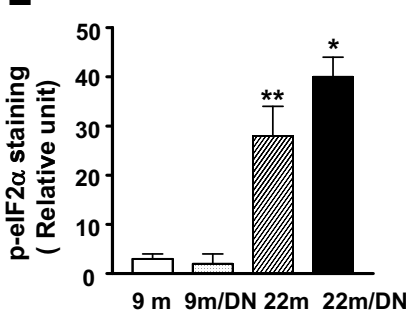

Figure 6. ER stress in the kidneys of 22-month-old diabetic mice. A: mRNA levels of GRP78, a marker for ER stress, were higher in kidneys of 22-month-old diabetic mice $(22 \mathrm{~m} / \mathrm{DN}$, *** $P<0.01$ versus 22 -month-old nondiabetic, $22 \mathrm{~m})$. B: CHOP mRNA levels were elevated in 9-month-old diabetic (9m/DN) and 22 -month-old nondiabetic kidneys and further increased in 22 -month-old diabetic kidneys. ${ }^{* *} P<0.01$ versus $9 \mathrm{~m}$; ${ }^{*} P<0.01$ versus $22 \mathrm{~m}$. C-F: Immunostaining for phosphorylated PERK of kidneys from 9-month-old $(\mathbf{C})$ (original magnification, $\times 500$ ), 9-month-old diabetic (D) (original magnification, $\times 500)$, 22-month-old (E) (original magnification, $\times 500$ ), and 22-month-old diabetic mice $(\mathbf{F})$ (original magnification, $\times 500$ ). The positive staining is seen in both glomerulus and tubules. The staining in 22-month-old nondiabetic kidney (E) is weaker than in 9-month-old nondiabetic kidney (C). However, 22-month-old diabetic kidney (F) shows the strongest staining among the groups. K: Quantification of the percentage of cells in renal cortex that were stained positive for phosphorylated (p) PERK showed that positive cell number was decreased in 22 -month-old nondiabetic $(22 \mathrm{~m})$ but increased in 22 -month-old diabetic mice. ${ }^{* * *} P<0.01$ versus 9 -month-old nondiabetic (9m). ${ }^{*} P<0.01$ versus 22 -month-old nondiabetic or 9-month-old diabetic (9m/DN). G-J: Immunostaining for phosphorylated eIF2 $\alpha$ in kidneys from 9-month-old $(\mathbf{G})$ (original magnification, $\times 500)$, 9-month-old diabetic $(\mathbf{H})$ (original magnification, $\times 500)$, 22-month-old $(\mathbf{I})($ original magnification, $\times 500)$, and 22-month-old diabetic (J) (original magnification, $\times 500$ ) mice. L: The staining is more intense in the kidneys of 22-month-old nondiabetic and 22-month-old diabetic mice. ${ }^{* *} P<0.01$ versus 9-month-old nondiabetic $(9 \mathrm{~m}) .{ }^{*} P<0.05$ versus 22 -month-old nondiabetic.

the 9- and 22-month-old controls and were reduced twofold in both young and old diabetic mice.

Lipid peroxidation, as indicated by MDA staining, was most evident in tubules (Figure 5, G-J). MDA staining in kidneys of 9-month-old mice was mild compared with that of kidneys of 9-month-old diabetic and 22-month-old nondiabetic mice (Figure 5, G-I). Intense staining was present in tubular cells of kidneys of 22-month-old diabetic mice (Figure 5J). Digital quantitation of the intensity of immunostaining supported the visual impression of an increase in nitrotyrosine and MDA staining in kidneys of 22-month-old diabetic mice (Figure 5, K and L).

\section{ER Stress}

ER stress has been shown to be present in the tubulointerstitium of patients with progressive diabetic nephropathy. ${ }^{23}$ Three regulatory pathways, namely PERK-elF2 $\alpha$, inositol-requiring enzyme $1-\mathrm{XBP}-1$, and activating transcription factor 6 , are critical in the ER stress response. ${ }^{24,25}$ The activation of activating transcription factor 6 increases GRP78 and the activation of PERK-elF2 $\alpha$ increases
CHOP transcription. CHOP mRNA levels were twofold increased in 9-month-old diabetic and 22-month-old nondiabetic mice, compared with 9-month-old nondiabetic mice (Figure 6). GRP78 and CHOP mRNA levels were elevated about twofold in the kidneys of 22-month old diabetic mice compared with those in the kidneys of 9-month-old diabetic and 22-month-old nondiabetic mice (Figure 6, A and B). The staining of phospho-PERK, which is normally present in glomeruli as well as in some of tubules of 9-month-old mice, was not different between the kidneys of 9-month-old nondiabetic and 9-month-old diabetic mice (Figure 6, C and D). Phospho-PERK staining was visibly decreased in kidneys of 22-month-old nondiabetic mice (Figure 6E). However, nearly $80 \%$ of cells in renal cortex showed positive staining in 22month-old diabetic mice (Figure 6F). PERK phosphorylates elF2 $\alpha{ }^{26,27}$ Surprisingly, the staining of phosphoelF2 $\alpha$ was strong in 22-month-old nondiabetic kidneys even though their phospho-PERK staining was weak, suggesting that increased elF2 $\alpha$ phosphorylation may be caused by kinase(s) other than PERK. ${ }^{28,29}$ There were no differences in phospho-elF2 $\alpha$ staining be- 
tween the kidneys of 9-month-old nondiabetic mice (Figure 6G) and 9-month-old diabetic mice (Figure 6H). Phospho-elF2 $\alpha$ staining was intensively increased in many tubular and interstitial cells of 22-month-old diabetic mice (Figure 6J).

Both oxidative stress and ER stress are known causes of cell death. A dose-dependent increase in apoptotic cell death was found in proximal tubular cells after exposure to $\mathrm{H}_{2} \mathrm{O}_{2}$, which induces oxidative stress, and to tunicamycin, which induces ER stress (data not shown). Thus, increased oxidative stress and the presence of ER stress may be causes of increased cell death in 22month-old diabetic kidneys.

\section{CHOP in ER Stress-Induced Cell Death, in Diabetic Nephropathy, and in Albuminuria in Aging}

$\mathrm{CHOP}$ is an important factor in ER stress-induced cell death. ${ }^{30}$ Because CHOP mRNA levels were the highest in 22-month-old diabetic kidneys, we asked whether $\mathrm{CHOP}$ contributed to ER stress-induced proximal tubular cell death. Proximal tubular cells isolated from $\mathrm{CHOP}^{-1-}$ and wild-type mice were treated with 0.6 to $1.2 \mu \mathrm{g} / \mathrm{ml}$ of tunicamycin in vitro. Whereas tunicamycin at 0.6 and 1.2 $\mu \mathrm{g} / \mathrm{ml}$ caused, respectively, 38 and $89 \%$ cell death in wild-type proximal tubular cells (Figure 7A), there was a $50 \%$ reduction in cell death in $\mathrm{CHOP}^{-1-}$ proximal tubular cells at these levels of tunicamycin treatment.

To further explore a role of CHOP in diabetic nephropathy, diabetes was induced by streptozotocin treatment in young $\mathrm{CHOP}$ knockout and wild-type mice. The glycemic levels were comparable between young $\mathrm{CHOP}^{-1-}$ $(353 \pm 56 \mathrm{mg} / \mathrm{dl})$ and wild-type $(397 \pm 42 \mathrm{mg} / \mathrm{dl})$ mice. The development of diabetes in young wild-type mice resulted in a modest (twofold) increase in urine albumin excretion (Figure 7B). However, young diabetic $\mathrm{CHOP}^{-1-}$ mice did not develop albuminuria. A moderate increase in the mesangial areas was present in some of glomeruli of young wild-type diabetic mice (Figure $7 \mathrm{C}$ ), whereas the glomeruli were largely normal in young $\mathrm{CHOP}^{-1-}$ diabetic mice (Figure 7D).

We also examined whether old male $\mathrm{CHOP}^{-1-}$ mice developed albuminuria. As expected, urine albumin excretion was significantly increased in 20-month-old wildtype male mice (Figure 7E). The levels of urinary albumin were significant lower in 20-month-old male $\mathrm{CHOP}^{-1-}$ mice. SDS-polyacrylamide gel electrophoresis analysis of urine further revealed an increase in protein(s) excretion at approximately $72 \mathrm{kDa}$ in wild-type aging male mice (Figure 7F).

\section{Inflammation}

As noted above, there is a prominent increase in inflammatory cells in the tubulointerstitium of 22-month-old diabetic mice (Figure 3F). Whereas few macrophages were present in 22-month-old nondiabetic mice kidneys (Figure $8 \mathrm{~A}$ ), macrophages accounted for a significant portion
A

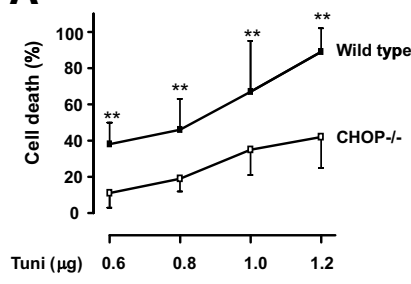

B
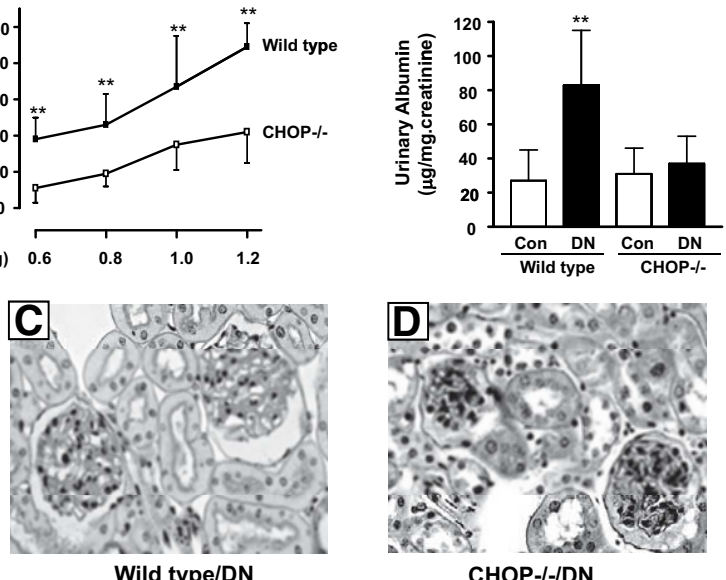

E

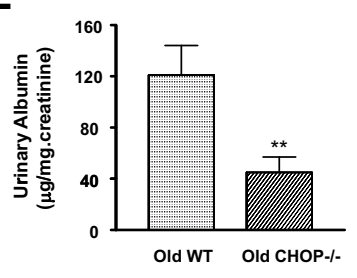

$\mathbf{F}$

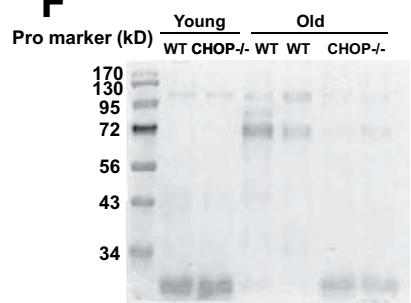

Figure 7. $\mathrm{CHOP}^{-/-}$proximal tubular cells, $\mathrm{CHOP}^{-/-}$diabetic mice, and $\mathrm{CHOP}^{-/-}$aging mice. A: $\mathrm{CHOP}^{-/-}$proximal tubular cells were relatively resistant to ER stress-induced cell death. Proximal tubular cells from wildtype and $\mathrm{CHOP}^{-1-}$ mice were treated with increasing concentration of tunicamycin (Tuni; $0.6-1.2 \mu \mathrm{g} / \mathrm{ml}$ ) for 24 hours. The percentage of cell death was quantitated. ${ }^{* * *} P<0.01$ versus $\mathrm{CHOP}^{-1-}$ cells at the same dosage. $\mathbf{B}$ $\mathrm{CHOP}^{-1-}$ and wild-type mice were made diabetic by streptozotocin, and mice were followed for 4 months. Urine albumin excretion was elevated in wild-type diabetic mice but not in $\mathrm{CHOP}^{-1-}$ diabetic mice. ${ }^{* *} P<0.01$ versus $\mathrm{CHOP}^{-/-}$diabetic mice. Con, control. C: Moderate expansion of the mesangial area is present in wild-type diabetic mice, whereas $\mathrm{CHOP}^{-/-}$diabetic glomeruli are nearly normal $($ D $)($ PAS $\times 200)$. E: Urine albumin excretion was increased in wild-type (WT) but not in $\mathrm{CHOP}^{-/-} 20$-month-old male mice. ${ }^{*} P(*)=0.01$. F: SDS-polyacrylamide gel electrophoresis analysis of urine samples from young (4-month-old wild-type and $\mathrm{CHOP}^{-/-}$) and old (20month-old wild-type and $\mathrm{CHOP}^{-/-}$) male mice. Note an increase in protein (Pro) at approximately $72 \mathrm{kDa}$ in two old wild-type mice.

of the infiltrating inflammatory cells in 22-month-old diabetic mice kidneys (Figure 8B). Macrophages were rarely seen in the kidneys of 9-month-old nondiabetic and 9-month-old diabetic mice. Although there was a modest increase in the expression of MCP-1, RANTES, MIP-2, CXCL-1, and ICAM-1 mRNAs in the kidneys of 9-monthold diabetic mice compared with kidneys of 9-month-old nondiabetic mice (Figure 8, C-G), the levels were higher in the kidneys of 22-month-old nondiabetic mice (the levels of MCP-1, RANTES, MIP-2, CXCL-1, and ICAM-1 mRNA were 2.6-, 2.1-, 7.8-, 9.2-, and 1.8-fold, respectively, higher than those in the kidneys of 9-month-old diabetic mice). The highest levels of these proinflammatory chemokines and adhesion molecule mRNAs were found in the kidneys of 22-month-old diabetic mice, except for MIP-2 (Figure 8E). Nuclear phosphorylated $\mathrm{NF}-\kappa \mathrm{B}$ staining, an indication of $\mathrm{NF}-\kappa \mathrm{B}$ activation, was present in interstitial capillary endothelial cells, parietal epithelial cells, and some cells of distal tubules and collecting ducts in the kidneys of normal 9-month-old nondiabetic mice (Figure $8 \mathrm{H}$ ). The moderately increased 

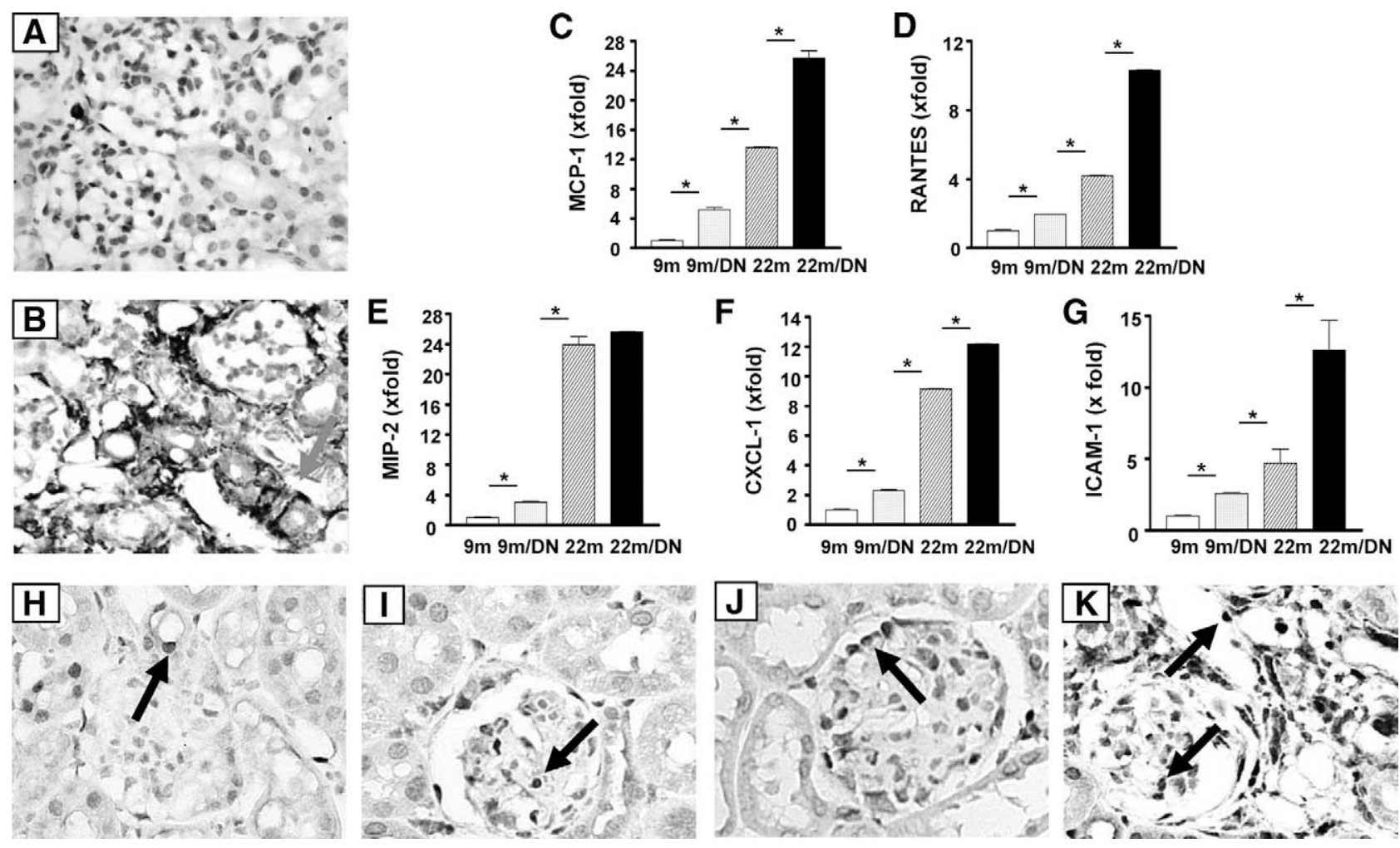

Figure 8. Proinflammatory gene expression and immunostaining for monocyte/macrophage and NF- $\kappa$ B. The presence of monocyte/macrophages in kidney was shown by F4/80 staining. Positive staining is barely seen in 9-month-old, 9-month-old diabetic (data not shown), and 22-month-old mouse kidneys (A). Extensive staining is present in the tubulointerstitium of 22-month-old diabetic mice (B). Arrow points to F4/80 positive cell. mRNA levels of MCP-1 (C), RANTES (D), MIP-2 (E), CXCL-1 (F), and ICAM-1 (G) in kidneys of 9-month-old $(9 \mathrm{~m})$, 9-month-old diabetic $(9 \mathrm{~m} / \mathrm{DN})$, 22-month-old (22m), and 22-month-old diabetic mice (22m/DN) were determined by real-time PCR and were corrected by $\beta$-actin mRNA levels at the same sample. The levels in the kidneys of 9-month-old mice were arbitrarily defined as 1. MCP-1, MIP-2, and CXCL-1 levels were significantly increased in the kidneys of 9-month-old diabetic mice and further increased in the kidney of 22-month-old mice. The levels of MCP-1, RANTES, CXCL-1, and ICAM-1 were increased more in the kidneys of 22-month-old diabetic mice compared with 22-month-old nondiabetic mice. ${ }^{*} P<0.01$. Nuclear staining of phosphorylated NF- $\kappa$ B (p65 [Ser-276]), a marker for NF- $\kappa$ B activation, shows positive cells (arrow) in the kidneys of 9-month-old $(\mathbf{H})$ (original magnification, $\times 500$ ), 9-month-old diabetic (I) (original magnification, $\times 500)$, 22-month-old $(\mathbf{J})($ original magnification, $\times 500$ ), and 22-month-old diabetic mice $(\mathbf{K})$ (original magnification, $\times 500$ ) mice. Although positive cells are not seen in glomeruli of 9-month-old nondiabetic mice, they are present in glomeruli of 9-month-old diabetic, 22-month-old, and 22-month-old diabetic mice (arrows). Positive cells are abundant in every field of kidneys of 22 -month-old diabetic mice, most noticeably in infiltrating cells.

number of NF-кB-positive nuclei in the kidneys of 9-month-old diabetic was localized mostly to glomeruli (Figure 8I). The number of positive nuclei in glomeruli in 22-month-old nondiabetic mice was sharply increased, and many podocytes appeared to be labeled (Figure 8J). The number of positive cells was markedly increased in both the glomeruli and tubulointerstitium of 22-month-old diabetic mice (Figure 8K).

\section{IL-6 and TNF- $\alpha$}

The cause(s) of chronic inflammation in the kidneys of 22-month-old diabetic mice were examined by evaluating the expression of IL-6 and TNF- $\alpha$, two cytokines that are actively involved in chronic inflammation in aging in humans. IL-6 mRNA levels were increased approximately fivefold in the kidneys of 9-month-old diabetic mice compared with those in the kidneys of 9-month-old nondiabetic mice (Figure 9A). The levels were further increased in the kidneys of 22-month-old nondiabetic mice and 22-month-old diabetic mice (Figure 9A). However, the levels of IL-6 mRNA in the kidneys of 22-month-old diabetic and 22-month-old nondiabetic mice did not differ (Figure 9A). Whereas circulating TNF- $\alpha$ levels were ele- vated in 4 of 1122 -month-old diabetic mice, the average levels were not statistically different among 9-month-old nondiabetic, 9-month-old diabetic, 22-month-old nondiabetic, and 22-month-old diabetic mice (data not shown). Because TNF- $\alpha$ mRNA expression was increased in the kidneys of 22-month-old diabetic mice (Figure 9B), we examined the responses in isolated tubular cells in vitro. We found that TNF- $\alpha$ stimulated MCP- 1 and RANTES mRNA and protein expression and CXCL-1, MIP-2, ICAM-1, and inducible NOS mRNA expression in proximal tubular cells, podocytes, and mesangial cells in vitro (Figure 9, C and D, and data not shown). Interestingly, TNF- $\alpha$ treatment also caused a twofold increase in GRP78 mRNA levels, a twofold increase in phosphorylated elF-2 $\alpha$, and a 2.2-fold increase in $\mathrm{CHOP}$ protein levels in proximal tubular cells (Figure 9, E and F), suggesting an induction of ER stress in these cells. This was associated with an increase in apoptotic cell death (Figure $9, \mathrm{G}-\mathrm{I}$ ). Although usually greater than $50 \mathrm{ng} / \mathrm{ml}$ TNF- $\alpha$ in combination with an inhibitor of protein synthesis is required for cell death in most other cell types, $25 \mathrm{ng} / \mathrm{ml}$ was sufficient to induce apoptosis in $24.5 \%$ of proximal tubular cells. The presence of DNA ladders and cleaved caspase 3 confirmed the proapoptotic action of TNF- $\alpha$ on 
A

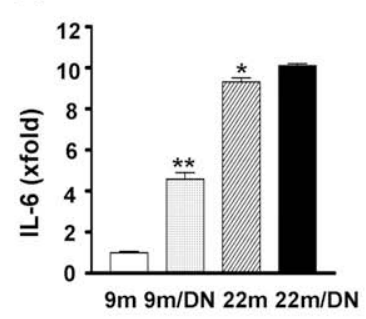

B

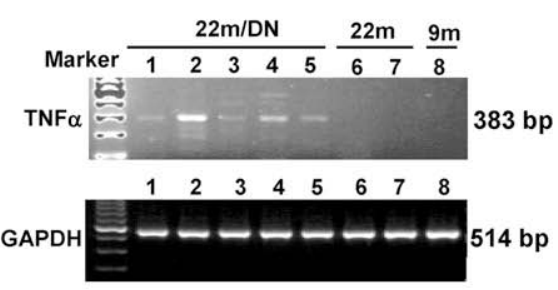

C

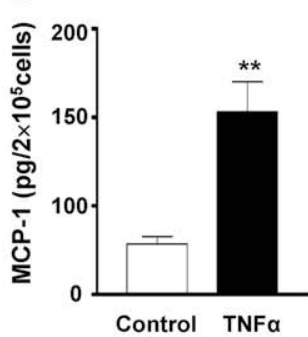

D

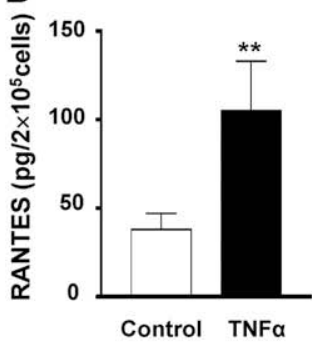

E

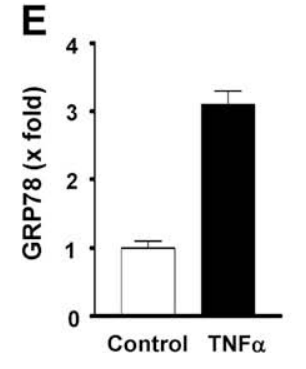

$\mathbf{F}$

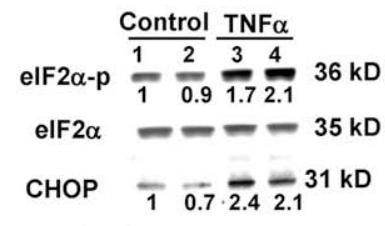

$\beta$-actin $-\sim-42 \mathrm{kD}$
G

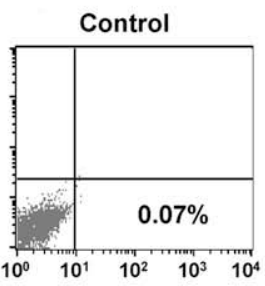

H

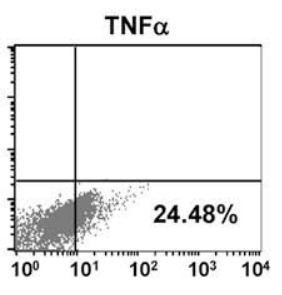

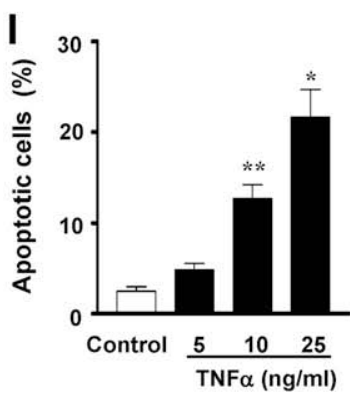
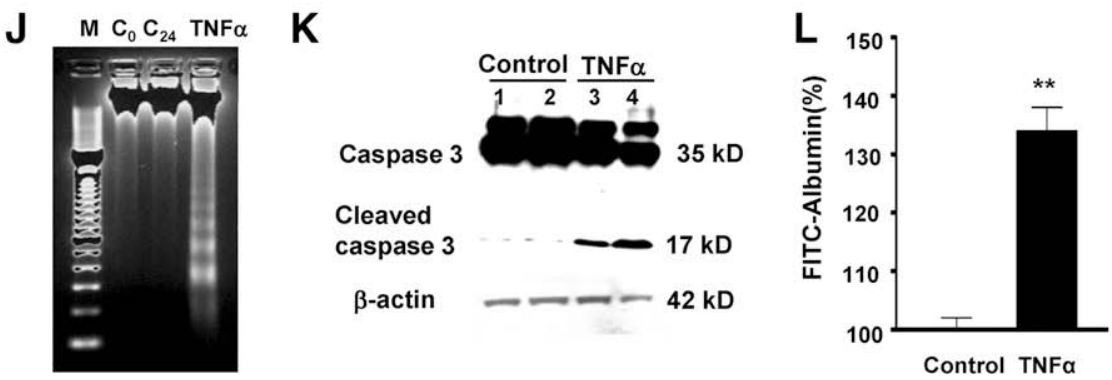

Figure 9. A: IL-6 expression: IL-6 mRNA levels were increased in 9-month-old diabetic (9m/DN) kidneys and further increased in 22 -month-old nondiabetic ( $22 \mathrm{~m})$ and 22 -month-old diabetic kidneys $(22 \mathrm{~m} / \mathrm{DN}) .{ }^{* *} P<0.01$ versus $9 \mathrm{~m} ;{ }^{*} P<0.01$ versus $9 \mathrm{~m} / \mathrm{DN}$. B: Representative gels of TNF- $\alpha$ and GAPDH mRNA levels of kidneys from 9 -month-old $(9 \mathrm{~m}), 9$-month-old diabetic $(9 \mathrm{~m} / \mathrm{DN}$, data not shown), 22-month-old (22m), and 22-month-old diabetic (22m/DN) mice. TNF- $\alpha$ mRNA expression was only found in the kidneys of 22-month-old diabetic mice (lanes $\mathbf{1}$ to 5). The expression was absent in 22-month-old (lanes $\mathbf{6}$ and 7) and 9-month-old (lane 8) mice even when PCR cycles were increased to 40. cDNA obtained from mouse macrophages (M $\phi$ ) was used as a positive control for PCR (data not shown). The levels of GAPDH mRNA were relative similar among the samples. C and D: TNF- $\alpha$ induced MCP-1 and RANTES protein production by proximal tubular cells. ${ }^{* *} P<0.01$ versus TNF- $\alpha$ alone. E: TNF- $\alpha$ increased GRP78 mRNA expression. GRP78 mRNA levels were measured by real-time PCR and corrected for $\beta$-actin mRNA levels. The levels in control cells were arbitrarily defined as 1 . F: TNF- $\alpha$ increased eIF $2 \alpha$ phosphorylation and CHOP. Proximal tubular cells were treated with TNF- $\alpha(25 \mathrm{ng} / \mathrm{ml})$ for 12 hours. Total eIF $2 \alpha$ was blotted using the same membrane after blotting with an antiphosphorylated eIF $2 \alpha$ antibody. Lane 1 and 2: control cells; lanes 3 and 4: TNF- $\alpha$-treated cells. G-I: TNF- $\alpha$-induced apoptosis in proximal tubular cells. Proximal tubular cells in the presence of $10 \%$ FBS were treated with TNF- $\alpha$ ( 5 to $25 \mathrm{ng} / \mathrm{ml}$ ) for 24 hours. Annexin V-positive cells in suspension or attached, counted by flow cytometry, are expressed as a percentage of total gated cells. Compared with control (G), TNF- $\alpha$ at a $25 \mathrm{ng} / \mathrm{ml}$ concentration caused $24.48 \%$ of cell death $(\mathbf{H})$. Note that TNF- $\alpha$ at a $10 \mathrm{ng} / \mathrm{ml}$ concentration was sufficient to induce significant cell death $(\mathbf{I}) .{ }^{* *} P<0.01$ versus untreated control; ${ }^{*} P<0.01$ versus cells treated with 10 ng/ml. J: DNA ladders. A representative agarose gel showing $2 \mu \mathrm{g}$ of DNA from control ( 0 hour and 24 hours) and TNF- $\alpha$ ( 25 ng/ml for 24 hours) is depicted. M, 100-bp DNA marker; $\mathrm{C}_{0}$, DNA collected at 0 hour; $\mathrm{C}_{24}$, DNA collected at 24 hours; TNF- $\alpha$, DNA collected at 24 hours after treatment. K: Caspase 3 . Proteins were collected from control (lane 1 and 2 ) and TNF- $\alpha$-treated $(25 \mathrm{ng} / \mathrm{ml}$ for 24 hours, lanes 3 and $\mathbf{4}$ ) cells and examined by Western blots of total and cleaved caspase 3 . The membranes was reblotted with an anti- $\beta$-actin antibody. L: TNF- $\alpha$ increased albumin permeability in podocytes. A monolayer of podocytes was created on the collagen-coated transwell filters in a 24-well plate. Some wells of cells were treated with TNF- $\alpha(20 \mathrm{ng} / \mathrm{ml})$. FITC-labeled BSA was added to the cells. The amount of fluorescence BSA that passed through the cell layer was quantitated. Negative controls included unlabeled BSA or the filter without cells. The experiments were repeated three times. The result shown is the fluorescence intensity 2 hours after the addition of FITC-BSA. The value of albumin flux through monolayer without TNF- $\alpha$ was arbitrarily defined as $100 \%$. ${ }^{* *} P<0.01$ versus control.

proximal tubular cells (Figure 9, J and K). In addition, TNF- $\alpha$ increased albumin permeability in podocytes cultured on collagen-coated transwell filters. The amount of FITC-labeled albumin that passed through the monolayer of podocytes was increased by $34 \%$ at 2 hours after TNF- $\alpha$ treatment (Figure 9L).

\section{Discussion}

The kidneys of aged humans and mice are more susceptible to injury than kidneys of younger individuals. ${ }^{31}$ In addition, older patients who develop acute kidney injury, particularly those who already have reduced renal function, are more likely to progress to end-stage renal disease. $^{32}$ The reasons for the increased susceptibility to injury and reduced ability to regain previous levels of renal function are unknown. However, the increased oxidant stress and inflammation in aging may render the aged kidney less able to deal with subsequent renal injuries, ,6,32 with resultant cell death rather than repair. We tested this postulate in 22-month-old C57B6 mice, because we have shown that C57B6 mice progressively develop reduced antioxidant reserves, increased expression of inflammatory cytokines, and insulin resistance 
with aging. ${ }^{6,33}$ Furthermore, glomerular mesangial cells from aged mice show stable phenotypic changes in vitro consisting of increased baseline reactive oxygen species and increased production of inflammatory cytokines and extracellular matrix. ${ }^{33,34}$ These biochemical changes are reflected in histological changes consisting of slowly progressive renal hypertrophy beginning at 18 months of age, mild to moderate mesangial expansion at 22 months, moderate albuminuria and tubulointerstitial lesions at 24 to 26 months, and severe albuminuria and glomerular and tubulointerstitial lesions at 30 months of age. ${ }^{13}$

We and others had previously shown that 8-month-old C57B6 mice were relatively resistant to the development of albuminuria and histological features of chronic renal disease, including diabetic nephropathy. ${ }^{12,13,22}$ In contrast to these findings in young mice, the current study shows that 22-month-old mice developed severe albuminuria, severe renal injury, and elevated serum creatinine levels after induction of hyperglycemia. This accentuated response is similar to the accelerated lesions we previously found after unilateral nephrectomy in 20month-old C57B6 mice. ${ }^{13}$ Thus, aging predisposes otherwise resistant mice to the development of progressive renal disease. This is similar to the situation in older patients subjected to stress during hospitalization. ${ }^{32}$

The renal lesions in 22-month-old diabetic mice included hyalinosis of afferent and efferent glomerular arterioles, increased thickness of glomerular basement membranes, a reduced number of glomerular fenestrations, expansion of mesangial areas, severe tubulointerstitial lesions, and inflammation, features typical of diabetic nephropathy in humans. ${ }^{35}$ The fact that the incidence of nephropathy in diabetic humans increases with age is mirrored by the findings in C57B6 mice. ${ }^{1,35,36}$ Thus, the use of 22-month-old diabetic C57B6 mice may allow the elucidation of the pathways important in the mechanisms underlying changes in the kidney induced by diabetes in aging.

Oxidative stress is probably an important contributor to diabetes-induced severe renal disease in aging mice. ${ }^{37}$ There was increased oxidative stress and accumulation of AGEs in the kidneys of 22-month-old mice. The increased oxidative stress present in 9-month-old diabetic kidneys was comparable to that in 22-month-old nondiabetic mice. These data are consistent with the fact that the degree and distribution of histological lesions were similar in the kidneys of 22-month-old nondiabetic and 9-month-old diabetic mice in the current study. The induction of hypoinsulinemia and hyperglycemia in 22month-old mice led to further elevations in the level of oxidative stress, which may have contributed to the severity of the lesions in 22-month-old diabetic mice by inducing or increasing apoptotic cell death. The tubulointerstitial compartment showed the most prominent increase in oxidative stress, as demonstrated by MDA and nitrotyrosine immunohistochemical staining. This was also the site of the greatest number of apoptotic cells. This association, together with the finding that hydrogen peroxide increased proximal tubular cell death in vitro, adds support to a role for oxidative stress in tubular cell death.

ER stress is another form of cell stress that is critically involved in several acute and chronic diseases. ${ }^{38}$ GRP78 is an important marker for ER stress. The facts that GRP78 mRNA levels were increased in 22-month-old diabetic kidneys and that this increase was associated with elevated levels of phosphorylated PERK and phosphorylated elF2 $\alpha$ strongly suggest that chronic ER stress was present in the kidneys of 22-month-old diabetic mice. ER stress has also been demonstrated in the tubulointerstitial compartment of patients with progressive diabetic nephropathy. ${ }^{23}$ Because the levels of $\mathrm{CHOP}$ mRNA were increased, but the levels of GRP78 were unchanged, it remains unclear whether ER stress was present in the kidneys of young diabetic mice. CHOP plays an important role in ER stress-induced cell death. ${ }^{30}$ $\mathrm{CHOP}$ transcription is increased in ER stress partly due to the activation of the PERK-elF2 $\alpha$ pathway. ${ }^{27,39}$ Because the kidneys of 22-month-old diabetic mice had the most significant increase in $\mathrm{CHOP}$ expression, we examined the contribution of $\mathrm{CHOP}$ to kidney cell death. We found that proximal tubular cells from $\mathrm{CHOP}$-deficient mice were resistant to ER stress-induced cell death. This result is consistent with the report that $\mathrm{CHOP}^{-1-}$ mice are resistant to acute ER stress kidney injury. ${ }^{40}$ Importantly, we found that $\mathrm{CHOP}$-deficient mice were also resistant to diabetic nephropathy. Song et $\mathrm{al}^{41}$ have reported that CHOP deletion in diabetic mice improved $\beta$-cell survival, insulin sensitivity, and antioxidant capacity. Together these data support a role for ER stress and CHOP in diabetes and diabetic nephropathy. $\mathrm{CHOP}$ may also play a role in kidney aging because male $\mathrm{CHOP}^{-\prime-}$ mice did not develop albuminuria as they aged.

Chronic tubulointerstitial lesions, characterized by inflammation and fibrosis, are a hallmark of progressive kidney diseases, including kidney aging and diabetic nephropathy. ${ }^{42}$ Severe tubulointerstitial lesions were present in the kidneys of aged diabetic mice in the current study. Because the up-regulation of MCP-1, CXCL-1, and MIP-2 mRNA expression in the kidneys of 22month-old nondiabetic mice occurred in the absence of an obvious inflammatory cell infiltrate, these data suggest that these changes in the expression of inflammatory cytokines were mainly derived from the parenchymal cells. The proinflammatory phenotype of parenchymal cells may play a role in the recruitment of inflammatory cells to the aging kidney. ${ }^{43}$ The expression of MCP-1, CXCL-1, RANTES, and ICAM-1 was further increased in the kidneys of aged diabetic mice and was associated with extensive NF- $\kappa \mathrm{B}$ activation. An increase in NF- $\kappa \mathrm{B}$ activation has also been shown in tubules and interstitium of diabetic patients with nephropathy. ${ }^{44}$ Interestingly, we found that TNF- $\alpha$ but not IL-6 mRNA levels were increased in the kidneys of 22-monthold diabetic mice. TNF- $\alpha$ is a well known strong inducer of NF- $\kappa$ B. Because TNF- $\alpha$ stimulates the expression of MCP-1, RANTES, CXCL-1, MIP-2, inducible NOS, and vascular cell adhesion molecule-1 in proximal tubular cells and other kidney cells, increased TNF- $\alpha$ may contribute to tubulointerstitial inflammation in 22-month-old 
mice with diabetes. Furthermore, we found that TNF- $\alpha$ stimulation led to increased GRP78 expression, elF2 $\alpha$ phosphorylation, and CHOP expression. Thus, TNF- $\alpha$ may cause ER stress in proximal tubular cells, which may contribute to the development of ER stress in the kidneys of aging diabetic mice. Moreover, the induction of ER stress by TNF- $\alpha$ was associated with apoptotic cell death. It is generally believed that suppression of protein synthesis is required for proapoptotic action of TNF- $\alpha$, because in most cell types TNF- $\alpha$ stimulates survival signal by activating NF- $\kappa B .{ }^{45}$ Further studies of whether survival signals are activated by TNF- $\alpha$ treatment in proximal tubular cells are required to dissect the molecular mechanisms of TNF- $\alpha$-induced cell death.

The current study suggests that part of the susceptibility of the aged kidney to increased oxidant stress after the induction of hyperglycemia is due to the preexistence of increased reactive oxygen species and inflammation in aging. ${ }^{3,4,6,34,41}$ ER stress and CHOP may also play an important role.

\section{References}

1. US Renal Data System: USRDS 2007 Annual Data Report. Bethesda, MD, National Institutes of Health, National Institute of Diabetes and Digestive and Kidney Diseases, 2007

2. Go AS, Chertow GM, Fan D, McCulloch CE, Hsu CY: Chronic kidney disease and the risks of death, cardiovascular events, and hospitalization. N Engl J Med 2004, 351:1296-305

3. Harman D: Free radical theory of aging: an update: increasing the functional life span. Ann NY Acad Sci 2006, 1067:10-21

4. Ruiz-Torres P, Lucio J, Gonzalez-Rubio M, Rodriguez-Puyol M, Rodriguez-Puyol D: Oxidant/antioxidant balance in isolated glomeruli and cultured mesangial cells. Free Radic Biol Med 1997, 22:49-56

5. Jiang T, Liebman SE, Lucia MS, Phillips CL, Levi M: Calorie restriction modulates renal expression of sterol regulatory element binding proteins, lipid accumulation, and age-related renal disease. J Am Soc Nephrol 2005, 16:2385-2394

6. Cai W, He JC, Zhu L, Chen X, Wallenstein S, Striker GE, Vlassara H: Reduced oxidant stress and extended lifespan in mice exposed to a low glycotoxin diet: association with increased AGER1 expression. Am J Pathol 2007, 170:1893-1902

7. Mitsui A, Hamuro J, Nakamura H, Kondo N, Hirabayashi Y, IshizakiKoizumi S, Hirakawa T, Inoue T, Yodoi J: Overexpression of human thioredoxin in transgenic mice controls oxidative stress and life span. Antioxid Redox Signal 2002, 4:693-696

8. Schriner SE, Linford NJ, Martin GM, Treuting P, Ogburn CE, Emond M, Coskun PE, Ladiges W, Wolf N, Van Remmen H, Wallace DC, Rabinovitch PS: Extension of murine life span by overexpression of catalase targeted to mitochondria. Science 2005, 308:1909-1911

9. Shinohara M, Thornalley PJ, Giardino I, Beisswenger P, Thorpe SR, Onorato J, Brownlee M: Overexpression of glyoxalase-I in bovine endothelial cells inhibits intracellular advanced glycation endproduct formation and prevents hyperglycemia-induced increases in macromolecular endocytosis. J Clin Invest 1998, 101:1142-1147

10. Vlassara $\mathrm{H}$, Palace MR: Diabetes and advanced glycation endproducts. J Intern Med 2002, 251:87-101

11. Sohal RS, Weindruch R: Oxidative stress, caloric restriction, and aging. Science 1996, 273:59-63

12. Zheng F, Striker GE, Esposito C, Lupia E, Striker LJ: Strain differences rather than hyperglycemia determine the severity of glomerulosclerosis in mice. Kidney Int 1998, 54:1999-2007

13. Zheng F, Plati AR, Potier M, Schulman $Y$, Berho M, Banerjee A, Leclercq B, Zisman A, Striker LJ, Striker GE: Resistance to glomerulosclerosis in B6 mice disappears after menopause. Am J Pathol 2003, 162:1339-1348

14. Brosius FC 3rd, Alpers CE, Bottinger EP, Breyer MD, Coffman TM, Gurley SB, Harris RC, Kakoki M, Kretzler M, Leiter EH, Levi M,
McIndoe RA, Sharma K, Smithies O, Susztak K, Takahashi N, Takahashi $\mathrm{T}$, Animal Models of Diabetic Complications Consortium: Mouse models of diabetic nephropathy. J Am Soc Nephrol 2009, 20:2503-2512

15. Lin JH, Walter P, Yen TS: Endoplasmic reticulum stress in disease pathogenesis. Annu Rev Pathol 2008, 3:399-425

16. Schlondorff DO: Overview of factors contributing to the pathophysiology of progressive renal disease. Kidney Int 2008, 74:860-866

17. Yuen PS, Dunn SR, Miyaji T, Yasuda H, Sharma K, Star RA: A simplified method for HPLC determination of creatinine in mouse serum. Am J Physiol Renal Physiol 2004, 286:F1116-F1119

18. Toyoda M, Najafian B, Kim Y, Caramori ML, Mauer M: Podocyte detachment and reduced glomerular capillary endothelial fenestration in human type 1 diabetic nephropathy. Diabetes 2007, 56:2155-2160

19. Neilson EG, McCafferty E, Feldman A, Clayman MD, Zakheim B, Korngold R: Spontaneous interstitial nephritis in kdkd mice. I. An experimental model of autoimmune renal disease. J Immunol 1984, 133:2560-2565

20. Sheridan AM, Schwartz JH, Kroshian VM, Tercyak AM, Laraia J, Masino S, Lieberthal W: Renal mouse proximal tubular cells are more susceptible than MDCK cells to chemical anoxia. Am J Physiol 1993 265:F342-F350

21. Wolf G, Neilson EG: Angiotensin II induces cellular hypertrophy in cultured murine proximal tubular cells. Am J Physiol 1990, 259:F768-777

22. Qi Z, Fujita H, Jin J, Davis LS, Wang Y, Fogo AB, Breyer MD: Characterization of susceptibility of inbred mouse strains to diabetic nephropathy. Diabetes 2005, 54:2628-2637

23. Lindenmeyer MT, Rastaldi MP, Ikehata M, Neusser MA, Kretzler M, Cohen CD, Schlöndorff D: Proteinuria and hyperglycemia induce endoplasmic reticulum stress. J Am Soc Nephrol 2008, 19:2225-2236

24. Rutkowski DT, Arnold SM, Miller CN, Wu J, Li J, Gunnison KM, Mori K, Sadighi Akha AA, Raden D, Kaufman RJ: Adaptation to ER stress is mediated by differential stabilities of pro-survival and pro-apoptotic mRNAs and proteins. PLoS Biol 2006, 4:2024-2041

25. Yamamoto K, Sato T, Matsui T, Sato M, Okada T, Yoshida H, Harada A, Mori K: Transcriptional induction of mammalian ER quality control proteins is mediated by single or combined action of ATF6 $\alpha$ and XBP1. Dev Cell 2007, 13:365-376

26. Harding HP, Zhang Y, Bertolotti A, Zeng H, Ron D: Perk is essential for translational regulation and cell survival during the unfolded protein response. Mol Cell 2000, 5:897-904

27. Ron D: Translational control in the endoplasmic reticulum stress response. J Clin Invest 2002, 110:1383-1388

28. Raven JF, Baltzis D, Wang S, Mounir Z, Papadakis Al, Gao HQ, Koromilas AE: PKR and PKR-like endoplasmic reticulum kinase induce the proteasome-dependent degradation of cyclin D1 via a mechanism requiring eukaryotic initiation factor $2 \alpha$ phosphorylation. J Biol Chem 2008, 283:3097-3108

29. Garcia-Barrio M, Dong J, Cherkasova VA, Zhang X, Zhang F, Ufano S, Lai R, Qin J, Hinnebusch AG: Serine 577 is phosphorylated and negatively affects the tRNA binding and elF2 $\alpha$ kinase activities of GCN2. J Biol Chem 2002, 277:30675-30683

30. Marciniak SJ, Yun CY, Oyadomari S, Novoa I, Zhang Y, Jungreis R, Nagata K, Harding HP, Ron D: CHOP induces death by promoting protein synthesis and oxidation in the stressed endoplasmic reticulum. Genes Dev 2004, 18:3066-3077

31. Chen G, Bridenbaugh EA, Akintola AD, Catania JM, Vaidya VS, Bonventre JV, Dearman AC, Sampson HW, Zawieja DC, Burghardt RC, Parrish AR: Increased susceptibility of aging kidney to ischemic injury: identification of candidate genes changed during aging, but corrected by caloric restriction. Am J Physiol Renal Physiol 2007, 293:F1272-F1281

32. Ishani A, Xue JL, Himmelfarb J, Eggers PW, Kimmel PL, Molitoris BA Collins AJ: Acute kidney injury increases risk of ESRD among elderly. J Am Soc Nephrol 2009, 20:223-228

33. Zheng F, Cheng QL, Plati AR, Ye SQ, Berho M, Banerjee A, Potier M, Jaimes EA, Yu H, Guan YF, Hao CM, Striker LJ, Striker GE: The glomerulosclerosis of aging in females: contribution of the proinflammatory mesangial cell phenotype to macrophage infiltration. Am J Pathol 2004, 165:1789-1798

34. Feng Z, Plati AR, Cheng QL, Berho M, Banerjee A, Potier M, Jy WC Koff A, Striker LJ, Striker GE: Glomerular aging in females is a multi- 
stage reversible process mediated by phenotypic changes in progenitors. Am J Pathol 2005, 167:355-363

35. Kimmelstiel P, Wilson C: intercapillary lesions in glomeruli of kidney. Am J Pathol 1936, 12:83-98

36. Huebschmann AG, Regensteiner JG, Vlassara H, Reusch JE: Diabetes and advanced glycoxidation end products. Diabetes Care 2006, 29:1420-1432

37. Vlassara H, Uribarri J, Cai W, Striker G: Advanced glycation end product homeostasis: exogenous oxidants and innate defenses. Ann NY Acad Sci 2008, 1126:46-52

38. Kim I, Xu W, Reed JC: Cell death and endoplasmic reticulum stress: disease relevance and therapeutic opportunities. Nat Rev Drug Discov 2008, 7:1013-1030

39. Ma Y, Brewer JW, Diehl JA, Hendershot LM: Two distinct stress signaling pathways converge upon the CHOP promoter during the mammalian unfolded protein response. J Mol Biol 2002, 318:1351-1365

40. Zinszner H, Kuroda M, Wang X, Batchvarova N, Lightfoot RT, Remotti $\mathrm{H}$, Stevens JL, Ron D: CHOP is implicated in programmed cell death in response to impaired function of the endoplasmic reticulum. Genes Dev 1998, 12:982-995
41. Song B, Scheuner D, Ron D, Pennathur S, Kaufman RJ: Chop deletion reduces oxidative stress, improves $\beta$ cell function, and promotes cell survival in multiple mouse models of diabetes. J Clin Invest 2008, 118:3378-3389

42. Schainuck LI, Striker GE, Cutler RE, Benditt EP: Structural-functional correlations in renal disease. II. The correlations. Hum Pathol 1970, 1:631-641

43. Wu J, Mei C, Vlassara H, Striker GE, Zheng F: Oxidative stressinduced JNK activation contributes to proinflammatory phenotype of aging diabetic mesangial cells. Am J Physiol Renal Physiol 2009, 297:F1622-F1631

44. Schmid H, Boucherot A, Yasuda Y, Henger A, Brunner B, Eichinger $F$ Nitsche A, Kiss E, Bleich M, Gröne HJ, Nelson PJ, Schlöndorff D, Cohen $\mathrm{CD}$, Kretzler M: Modular activation of nuclear factor $-\kappa \mathrm{B}$ transcriptional programs in human diabetic nephropathy. Diabetes 2006, 55:2993-3003

45. Kamata H, Honda S, Maeda S, Chang L, Hirata H, Karin M: Reactive oxygen species promote TNF $\alpha$-induced death and sustained JNK activation by inhibiting MAP kinase phosphatases. Cell 2005, 120:649-661 